\title{
Midnight sector observations of auroral omega bands
}

\author{
J. A. Wild, ${ }^{1}$ E. E. Woodfield, ${ }^{1}$ E. Donovan, ${ }^{2}$ R. C. Fear, ${ }^{3}$ A. Grocott, ${ }^{3}$ M. Lester, ${ }^{3}$ \\ A. N. Fazakerley, ${ }^{4}$ E. Lucek, ${ }^{5}$ Y. Khotyaintsev, ${ }^{6}$ M. Andre, ${ }^{6}$ A. Kadokura, ${ }^{7}$ \\ K. Hosokawa, ${ }^{8}$ C. Carlson, ${ }^{9}$ J. P. McFadden, ${ }^{9}$ K. H. Glassmeier, ${ }^{10}$ V. Angelopoulos, ${ }^{11}$ \\ and G. Björnsson ${ }^{12}$
}

Received 30 June 2010; revised 10 December 2010; accepted 5 January 2011; published 18 March 2011.

[1] We present observations of auroral omega bands on 28 September 2009. Although generally associated with the substorm recovery phase and typically observed in the morning sector, the features presented here occurred just after expansion phase onset and were observed in the midnight sector, dawnward of the onset region. An all-sky imager located in northeastern Iceland revealed that the omega bands were $\sim 150 \times 200 \mathrm{~km}$ in size and propagated eastward at $\sim 0.4 \mathrm{~km} \mathrm{~s}^{-1}$ while a colocated ground magnetometer recorded the simultaneous occurrence of Ps6 pulsations. Although somewhat smaller and slower moving than the majority of previously reported omega bands, the observed structures are clear examples of this phenomenon, albeit in an atypical location and unusually early in the substorm cycle. The THEMIS C probe provided detailed measurements of the upstream interplanetary environment, while the Cluster satellites were located in the tail plasma sheet conjugate to the ground-based all-sky imager. The Cluster satellites observed bursts of $0.1-3 \mathrm{keV}$ electrons moving parallel to the magnetic field toward the Northern Hemisphere auroral ionosphere; these bursts were associated with increased levels of field-aligned Poynting flux. The in situ measurements are consistent with electron acceleration via shear Alfvén waves in the plasma sheet $\sim 8 R_{E}$ tailward of the Earth. Although a one-to-one association between auroral and magnetospheric features was not found, our observations suggest that Alfvén waves in the plasma sheet are responsible for field-aligned currents that cause Ps6 pulsations and auroral brightening in the ionosphere. Our findings agree with the conclusions of earlier studies that auroral omega bands have a source mechanism in the midtail plasma sheet.

Citation: Wild, J. A., et al. (2011), Midnight sector observations of auroral omega bands, J. Geophys. Res., 116, A00I30, doi:10.1029/2010JA015874.

\footnotetext{
${ }^{1}$ Physics Department, Lancaster University, Lancaster, UK.

${ }^{2}$ Department of Physics and Astronomy, University of Calgary, Calgary, Alberta, Canada.

${ }^{3}$ Department of Physics and Astronomy, University of Leicester, Leicester, UK.

${ }^{4}$ Mullard Space Science Laboratory, University College London, Holmbury St. Mary, UK.

${ }^{5}$ Department of Physics, Imperial College London, London, UK.

${ }^{6}$ Swedish Institute of Space Physics, Uppsala, Sweden.

${ }^{7}$ National Institute of Polar Research, Tokyo, Japan.

${ }^{8}$ Department of Information and Communication Engineering, University of Electro-Communications, Tokyo, Japan.

${ }^{9}$ Space Sciences Laboratory, University of California, Berkeley, USA.

${ }^{10}$ Institut für Geophysik und Extraterrestrische Physik, Technische Universität Braunschweig, Braunschweig, Germany.

${ }^{11}$ ESS, Institute of Geophysics and Planetary Physics, University of California, Los Angeles, California, USA.

${ }^{12}$ Science Institute, University of Iceland, Reykjavik, Iceland.

\section{Introduction}

[2] Auroral omega bands were first reported as a distinct class of auroral structure by Akasofu and Kimball [1964]. Originally, the name referred to the distinct, undulating shape of the auroral arc, which resembled an inverted Greek letter $\Omega$. However, over nearly 50 years of usage, the classification has gradually evolved. For example, whereas Akasofu and Kimball's omega bands were distorted arcs, Lyons and Walterscheid [1985] presented observations of omega bands with a dark, inverted $\Omega$ shape formed by bright torches extending poleward from the auroral oval, and Opgenoorth et al. [1994] reported "streets" of multiple omega band structures in which undulations on the poleward boundary gave rise to alternating bright humps and dark bays. Lühr and Schlegel [1994] described omega bands as "a luminous band from which tongue-like protrusions extend toward the north" with the bright tongues shaped like a Greek $\Omega$ and the dark area separating adjacent tongues shaped like an inverted $\Omega$. In recent research, the term omega band has been used to described all of the above 

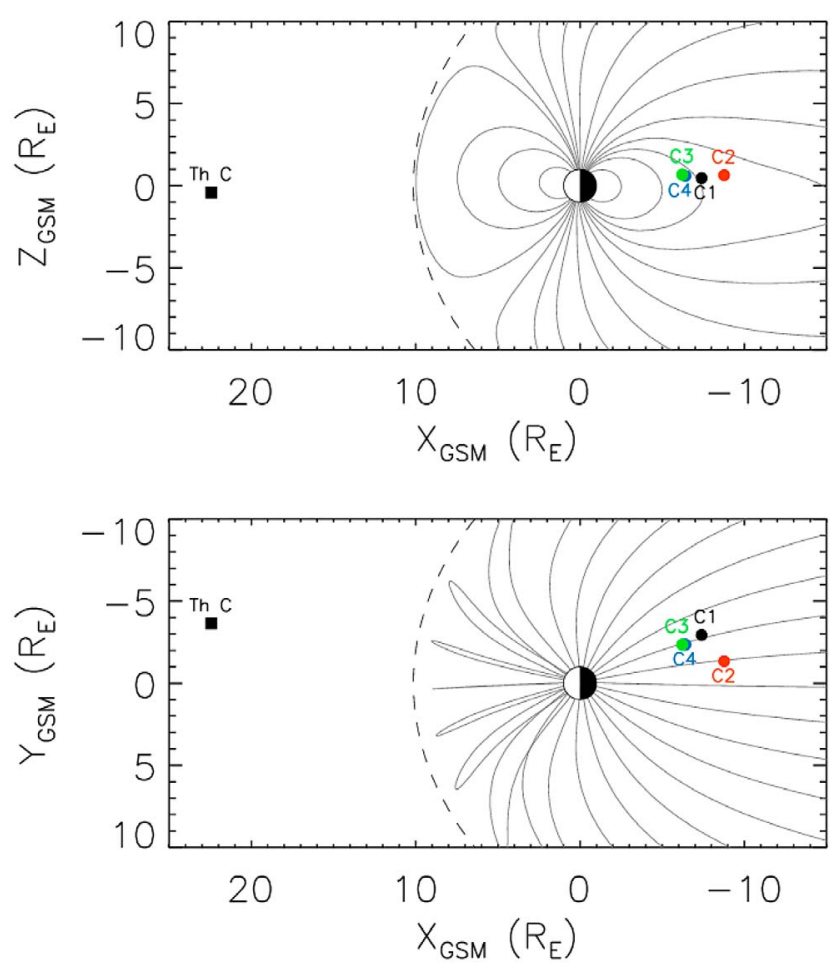

Figure 1. Locations of the THEMIS and Cluster spacecraft used in this study at 0000 UT on 28 September 2009, projected into the GSM (top) $\mathrm{X}-\mathrm{Z}$ and (bottom) $\mathrm{X}-\mathrm{Y}$ planes. Magnetic field lines derived from the T01 magnetospheric field model and the modeled magnetopause location are also shown, as described in the text.

variants on what is assumed to be the same basic auroral structure [Syrjäsuo and Donovan, 2004; Safargaleev et al., 2005; Vanhamäki et al., 2009].

[3] Regardless of the exact auroral configuration, omega bands exhibit many common properties. Omega bands and magnetic pulsations in the Ps6 wave band (4-40 min periodicity) are usually observed simultaneously [Kawasaki and Rostoker, 1979; André and Baumjohann, 1982], with magnetic disturbances interpreted as evidence of the passage of field-aligned currents within the auroral structures [ $L \ddot{u} h r$ and Schlegel, 1994; Wild et al., 2000]. Omega bands, typically $400-1000 \mathrm{~km}$ in size, are usually observed propagating eastward (i.e., dawnward) at speeds of $0.4-2 \mathrm{~km} \mathrm{~s}^{-1}$ in the morning sector auroral zone and are generally associated with the recovery phase of magnetospheric substorms [e.g., Vanhamäki et al., 2009, and references therein].

[4] While the distribution of quasi-stationary, fieldaligned currents within omega bands is broadly understood [Lühr and Schlegel, 1994; Wild et al., 2000; Amm et al., 2005; Kavanagh et al., 2009], the mechanism responsible for omega band formation remains unclear. The reader is directed to Amm et al. [2005] for a useful review of the various models proposed to explain omega band generation. These models include energetic particle precipitation in the morning sector originating from the outer edge of the ring current region [Opgenoorth et al., 1994], an electrostatic interchange instability developing at the poleward (tailward) edge of a torus of hot plasma in the near-Earth magneto- sphere during the substorm recovery phase [Yamamoto et al., 1997], and the structuring of magnetic vorticity and field-aligned currents via the Kelvin-Helmholtz instability [Janhunen and Huuskonen, 1993].

[5] In this paper, we present space- and ground-based measurements of omega bands observed during the night of 27-28 September 2009. The omega bands studied are slightly unusual in that they were observed in the midnight (21-03 MLT) sector ionosphere, rather than the morning (03-09 MLT) sector, and occurred shortly after a substorm expansion phase onset/intensification (rather than during a substorm recovery phase). Our investigation of these somewhat atypical omega bands reveals that unlike previously reported examples, they are relatively small and slow moving. Although in situ field and plasma measurements from the conjugate region of the magnetosphere indicated enhanced but variable Alfvénic Poynting flux and bursts of field-parallel moving electrons, a clear one-to-one correspondence with individual omega bands was not observed. In the this paper, we first introduce the experimental instrumentation used in our study, then present the upstream, ground- and space-based observations before discussing and summarizing our findings.

\section{Instrumentation}

[6] Figure 1 shows the disposition of spacecraft used in this study. Upstream solar wind and interplanetary magnetic field (IMF) conditions were provided by a single probe of the NASA Time-History of Events and Macroscale Interactions during Substorms (THEMIS) mission [Angelopoulos, 2008]; magnetospheric plasma and magnetic field measurements came from the four satellites of the ESA Cluster mission [Escoubet et al., 1997, 2001]. Figure 1 shows the location of these spacecraft at 0000 UT on 28 September 2009 in the $\mathrm{X}-\mathrm{Z}$ and $\mathrm{X}-\mathrm{Y}$ GSM planes, with the position of each indicated by the labeled symbols. Also indicated for reference are magnetic field lines derived from the Tsyganenko 2001 model [Tsyganenko, 2002a, 2002b], hereafter referred to as the T01 model, and a model magnetopause [after Shue et al. 1997]. The solar wind and IMF parameterization of these models is discussed further in section 3. The present study exploits ion plasma data from the electrostatic analyzer (ESA [McFadden et al., 2008a, 2008b]) and magnetic field data from the fluxgate magnetometer (FGM [Auster et al., 2008]) on the THEMIS C probe in order to monitor the solar wind and IMF, respectively. During the interval of interest, THEMIS C (indicated by the black square in Figure 1) was located in the solar wind $\sim 22 R_{E}$ upstream of the Earth, approximately in the Earth's orbital plane but offset from the Sun-Earth line by $\sim 4 R_{E}$ in the dawnward direction.

[7] At 0000 UT on 28 September 2009, the four Cluster satellites were moving tailward and southward toward apogee in the postmidnight sector magnetosphere. Clusters 1, 3 and 4 (indicated by the black, green and blue circles, respectively) were located in the northern tail lobe between 6 and $8 R_{E}$ downtail of the Earth at $\sim 0130$ magnetic local time (MLT). Cluster 2 (indicated by the red circle) was somewhat farther downtail at a radial distance $\sim 9 R_{E}$ and a slightly earlier magnetic local time of $\sim 0040$ MLT. In this study we exploit magnetic field measurements made by the 


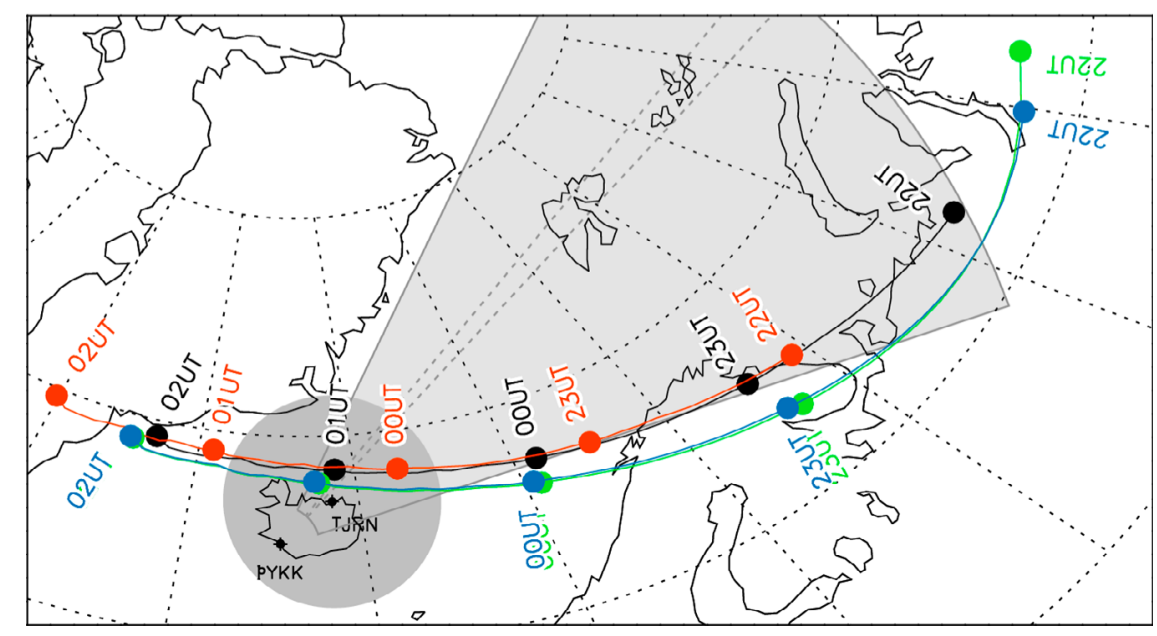

Figure 2. The arrangement of ground-based experiments employed in this study. Coastlines are projected in a polar geographic coordinate system, with parallels of constant geomagnetic latitude overlaid at $80^{\circ}, 70^{\circ}, 60^{\circ}$ and $50^{\circ}$ north and geomagnetic meridians overlaid at $15^{\circ}$ intervals (dotted lines). The light and dark gray shaded areas show the fields of view of the SuperDARN Iceland East and Tjörnes Rainbow ASI, respectively. The locations of the Tjörnes ASI (labeled TJRN) and the Iceland East radar site at Pykkvibær (labeled PYKK) are also indicated. Colored arcs show the magnetic footprints at $110 \mathrm{~km}$ altitude of the four Cluster satellites, color-coded as in Figure 1 (black, C1; red, C2; green, C3; blue, C4) with solid circular tick marks indicating each satellite's position at hourly intervals (note that the 0100 UT tick mark labels for $\mathrm{C} 3$ and $\mathrm{C} 4$ are omitted for clarity).

Cluster fluxgate magnetometer experiment (FGM [Balogh et al., 1997, 2001]), electron plasma observations made by the Cluster plasma electron and current experiment (PEACE [Johnstone et al., 1997; Owen et al., 2001]) and electric field measurements from the electric fields and waves instrument (EFW [Gustafsson et al., 1997, 2001]).

[8] Ground-based auroral observations were provided by a new all-sky imager (ASI) located on the Tjörnes peninsula in northeastern Iceland $\left(66.2^{\circ} \mathrm{N}, 17.1^{\circ} \mathrm{W}\right.$, geographic coordinates). This color "Rainbow" imager [Partamies et al., 2007] is similar in both design and operation to those of the THEMIS ground-based observatory (GBO) array; the main difference is the use of a color CCD imager to provide color all-sky images (THEMIS GBOs produce only gray scale images). Images are automatically recorded at a rate of 10 frames per minute during hours of darkness, yielding a $6 \mathrm{~s}$ cadence. Two additional imagers deployed at Pykkvibær (southwestern Iceland) and Tórshavn (Faroe Isles) were not used in this study due to unfavorable weather conditions at those sites during the period of interest.

[9] Observations of ionospheric flow were derived from the Iceland East radar of the Super Dual Auroral Radar Network (SuperDARN [Chisham et al., 2007]). This coherent scatter, high-frequency radar, located at Pykkvibær in southwestern Iceland, one half of the Co-operative UK Twin-Located Auroral Sounding System radar pair (CUTLASS [Lester et al., 2004]), has a field of view (FOV) that extends northeastward, covering an area over $3 \times$ $10^{6} \mathrm{~km}^{2}$. In standard operations the FOV comprises 16 discrete beams separated by $3.24^{\circ}$ in azimuth, with each beam subdivided into 75 individual range bins $45 \mathrm{~km}$ in length. Like all SuperDARN radars, the Iceland East radar is a frequency agile system $(8-20 \mathrm{MHz})$ that routinely measures the line-of-sight (LOS) Doppler velocity and spectral width of, and the backscattered power from, ionospheric plasma irregularities. However, this particular radar has been equipped with a so-called "stereo" capability, enabling two beams to be sounded simultaneously by interleaving two transmitted pulse sequences at slightly offset frequency channels. During the interval of interest, the stereo capability was deployed to sound the full FOV (i.e., scanning through beams $0,1,2,3 . .15$ in sequence) using channel $\mathrm{A}$ while sounding only one beam direction (beam 5) using channel B. Given a $3 \mathrm{~s}$ dwell time on each beam (and allowing for radar integration and minute timing synchronization with other SuperDARN radars), this mode returned a full scan of the complete FOV every minute (via channel A) and measurements along the high-resolution beam every $3 \mathrm{~s}$ (via channel B). In this study, we shall focus on measurements from the high time resolution channel (B).

[10] Finally, to reveal the magnetic perturbations associated with auroral features observed by the above experiments, we exploit $1 \mathrm{~s}$ resolution ground magnetic field measurements from a fluxgate magnetometer colocated with the Tjörnes Rainbow ASI and deployed by the Japanese National Institute of Polar Research (NIPR) [Sato and Saemundsson, 1984].

[11] Figure 2 shows the distribution of the instruments employed in this study. The FOV of the Tjörnes ASI is indicated by the shaded dark gray circle. Specifically, this corresponds to the FOV projected to $110 \mathrm{~km}$ altitude and for look directions within $80^{\circ}$ of the zenith (disregarding the portion of the FOV within $10^{\circ}$ of the horizon where line-ofsight projection gives rise to the greatest uncertainties). The full FOV of the Iceland East SuperDARN radar (sounded by channel A) is shown by the light gray shaded region, with the high time resolution beam (beam 5 , sounded by channel B) outlined by the gray dotted lines. The locations 
of the Tjörnes ASI/magnetometer and pykkvibær radar sites are indicated by crossed circles labeled "TJRN" and "PYKK", respectively.

[12] For reference, the magnetic footprints of the Cluster satellites during the interval from 2200 UT (on 27 September) to $0200 \mathrm{UT}$ (on 28 September) are superimposed on Figure 2. Each satellite's footprint, computed at an altitude of $110 \mathrm{~km}$ using the T01 magnetic field model, is colorcoded as in Figure 1 with locations indicated at hourly intervals. The T01 model was selected because it has been optimized to represent the inner and near magnetosphere region $\left(X_{G S M} \geq-15 R_{E}\right)$ for different interplanetary conditions and ground disturbance levels [Tsyganenko, 2002a, $2002 b]$. To generate the footprint for each satellite, location information is extracted from the Cluster FGM data set at a temporal resolution of $1 \mathrm{~s}$. The most recent upstream $\left(P_{S W}\right.$, IMF $B_{Y}$, IMF $B_{Z}$ observed by THEMIS C) and geomagnetic (Dst) data are then selected as inputs to calculate the footprint positions at a $1 \mathrm{~s}$ resolution.

\section{Observations}

\subsection{Interplanetary Conditions}

[13] Figure 3 presents an overview of upstream interplanetary magnetic field (IMF) and solar wind conditions for the $4 \mathrm{~h}$ interval spanning midnight on 28 September. These measurements, recorded by the THEMIS $\mathrm{C}$ probe, are important in two key respects. First, they indicate the likely energy and momentum input to the magnetosphere during the interval in question. Second, these upstream observations parameterize the T01 magnetic field model used to estimate the magnetic footprints of the Cluster satellites (as shown in Figures 1 and 2). Of particular relevance are the solar wind plasma and interplanetary magnetic field engulfing the dayside magnetosphere. As such, the data presented in Figure 3 are time shifted (or lagged) to account for the Earthward propagation from the point of measurement to the dayside magnetopause. For this study, based upon the probe's location ( $\sim 12 R_{E}$ upstream of the magnetopause) and the observed solar wind plasma velocity, upstream parameters from THEMIS $\mathrm{C}$ are lagged by $+3 \mathrm{~min}$ in order to present the solar wind and IMF conditions impinging upon the dayside magnetopause.

[14] The $B_{Z}$ component of the IMF was directed southward almost continuously throughout this interval (with a brief northward excursion at $0030 \mathrm{UT}$ ) while the IMF $B_{Y}$ component was positive (duskward). Given the generally similar magnitudes of both components, this resulted in an IMF clock angle (defined as $\arctan \left(B_{Y} / B_{Z}\right)$ ) of $\sim 135^{\circ}$ throughout the interval. The $B_{X}$ component was positive throughout (except for a brief negative excursion at $2220 \mathrm{UT}$ ), indicating that IMF phase fronts were tilted toward the Earth and the overall interplanetary magnetic field magnitude remained between 2.0 and $3.5 \mathrm{nT}$. The antisunward ion velocity typically $\sim 325 \mathrm{~km} \mathrm{~s}^{-1}$ declined sightly over the $4 \mathrm{~h}$ interval, while the ion density increased gradually from 12 to $15 \mathrm{~cm}^{-3}$. As a result, the solar wind pressure varied between 2 and $3 \mathrm{nPa}$.

\subsection{Auroral and Ground-Based Measurements}

[15] Figure 4 presents an overview of the ground-based measurements used in this study. Figure 4a shows iono- spheric LOS Doppler velocity measured along the high time resolution beam (beam 5) of the SuperDARN Iceland East radar, plotted as a function of universal time and magnetic latitude. Velocity measurements are color-coded according to the color bar on the right side, with positive (green/blue) velocities directed toward the radar and negative (yellow/ red) velocities directed away from it. The magnetic latitude of the ASI zenith is indicated by a dashed horizontal line. Given the orientation of the radar FOV (as indicated in Figure 2), beam 5 does not exactly overlook the Tjörnes Rainbow ASI site. Relative to the ASI zenith, beam 5 crosses the ASI magnetic latitude $\sim 50 \mathrm{~km}$ westward of the site and crosses the ASI magnetic meridian $\sim 50 \mathrm{~km}$ northward of it. Throughout the interval, backscatter was observed at various ranges, but after $\sim 2330 \mathrm{UT}$, a persistent band of backscatter was observed between $66.5^{\circ}$ and $67.5^{\circ}$ (highlighted by the dotted horizontal lines). Figure $4 \mathrm{~b}$ presents a time series of LOS velocity, averaged over range gates between these latitudes. The vertical axis has been reversed such that negative velocities (corresponding to poleward motion) are represented by values increasing toward the top of the page.

[16] Figure $4 \mathrm{c}$ is a keogram derived from the magnetic meridian of the Tjörnes ASI. For clarity, these data have been presented in an inverted gray scale such that areas of dark shading correspond to bright auroral emission. Brightness is presented in a system of arbitrary units because the Rainbow ASI system does not yield calibrated brightness measurements. The magnetic latitude of the ASI's zenith and the upper/lower boundaries over which SuperDARN ionospheric radar velocities are averaged are overlaid onto the keogram as dashed and dotted horizontal lines, respectively. It should be noted that at the Tjörnes ASI site, magnetic local time is approximately the same as local time (MLT $=\mathrm{UT}+$ $14 \mathrm{~min}$ ) such that the universal time annotation on the horizontal axis is a reasonable approximation to the magnetic local time of the meridional observations. Italicized numerals/ letters indicate features discussed below.

[17] Figures $4 \mathrm{~d}-4 \mathrm{~g}$ show magnetic field data from the NIPR fluxgate magnetometer located at Tjörnes (i.e., colocated with the Rainbow ASI). Figure 4d presents unfiltered "raw" magnetometer data with the $\mathrm{H}$ component (black trace and left scale) directed toward magnetic north and the D component (red trace and right scale) directed orthogonally eastward within the horizontal plane. Figures $4 \mathrm{e}$ and $4 \mathrm{f}$ present the same magnetometer data, but band-pass filtered to reveal fluctuations in the Ps6 pulsation range (with periods between 4 and $40 \mathrm{~min}$ ) and the $\mathrm{Pi} 2$ pulsation range (with periods between 40 and $150 \mathrm{~s}$ ), respectively. To study the current structures that underlie these magnetic fluctuations, it is necessary to derive a sequence of equivalent current vectors. For an $E$ region current system with a spatial extent greater than the $E$ region height, and assuming a horizontally uniform ionospheric conductivity, the ground magnetic field deflections, b, can be related to an ionospheric equivalent current density, $\mathbf{J}$, by

$$
J_{H}=-\frac{2}{\mu_{0}} b_{D} \text { and } J_{D}=\frac{2}{\mu_{0}} b_{H}
$$

where the $H$ and $D$ subscripts indicate the geomagnetic northward and eastward components, respectively [Lühr 


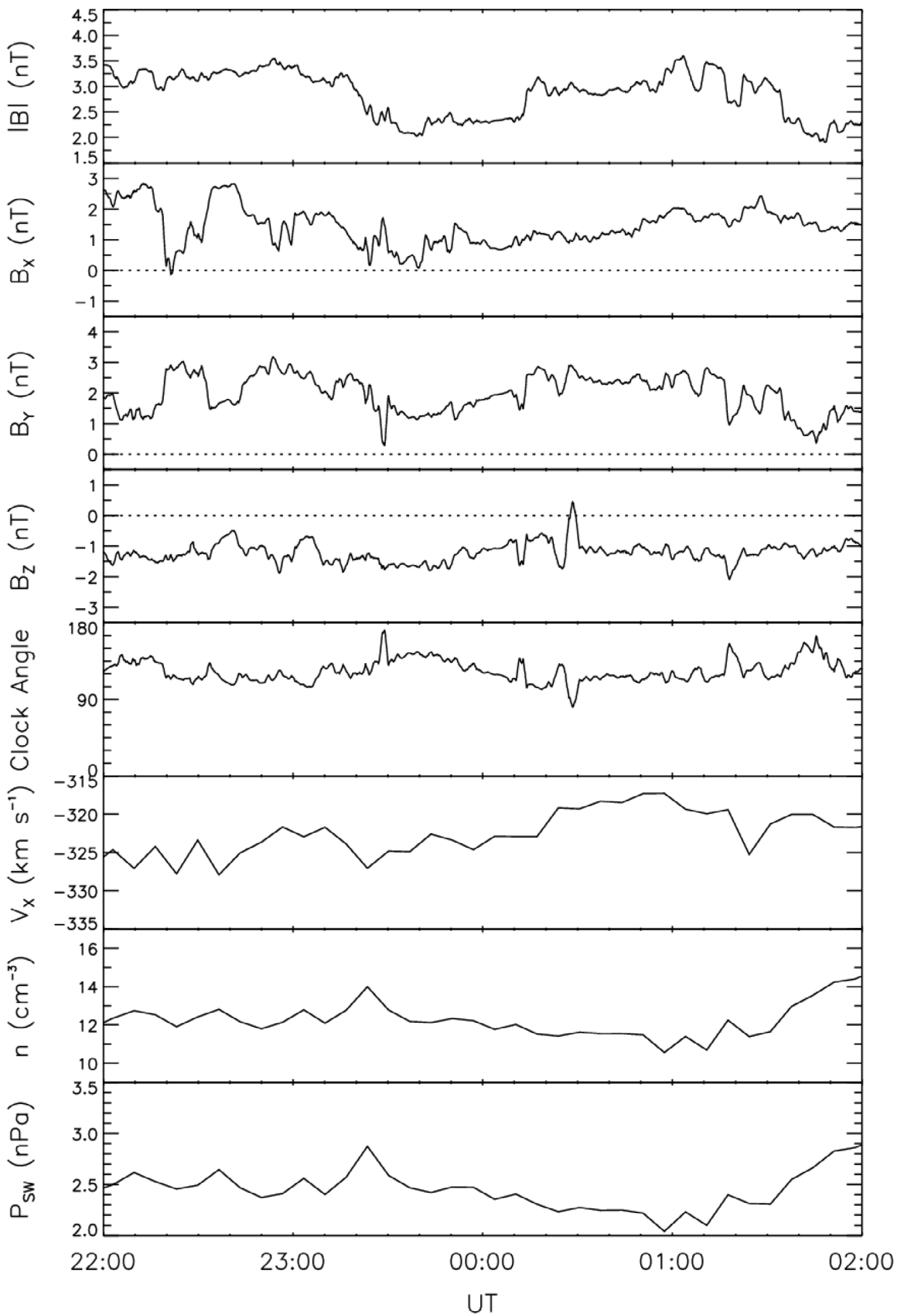

Figure 3. Upstream solar wind and IMF conditions between 2200 UT (on 27 September) and 0200 UT (on 28 September) observed by the THEMIS $C$ probe. From top to bottom, the interplanetary magnetic field strength; $B_{X}, B_{Y}, B_{Z}$ components; IMF clock angle (all in GSM coordinates); plasma ion velocity in the $X_{G S M}$ direction; ion density; and solar wind dynamic pressure. Data are lagged in time by $3 \mathrm{~min}$ in order to show conditions at the magnetopause as a function of UT. 
and Schlegel, 1994]. Figure 4g therefore presents equivalent current vectors derived from Tjörnes magnetometer data, preprocessed by bandpass filtering to retain Ps6 pulsations (as in Figure 4e). Equivalent current vectors pointing ver- tically (horizontally) on the page correspond to northward (eastward) currents, and an eastward $0.1 \mathrm{~A} \mathrm{~m}^{-1}$ equivalent current vector is shown for scale. For context, Figures $4 \mathrm{~h}$ and $4 \mathrm{i}$ show time series of the auroral electrojet $(A E)$

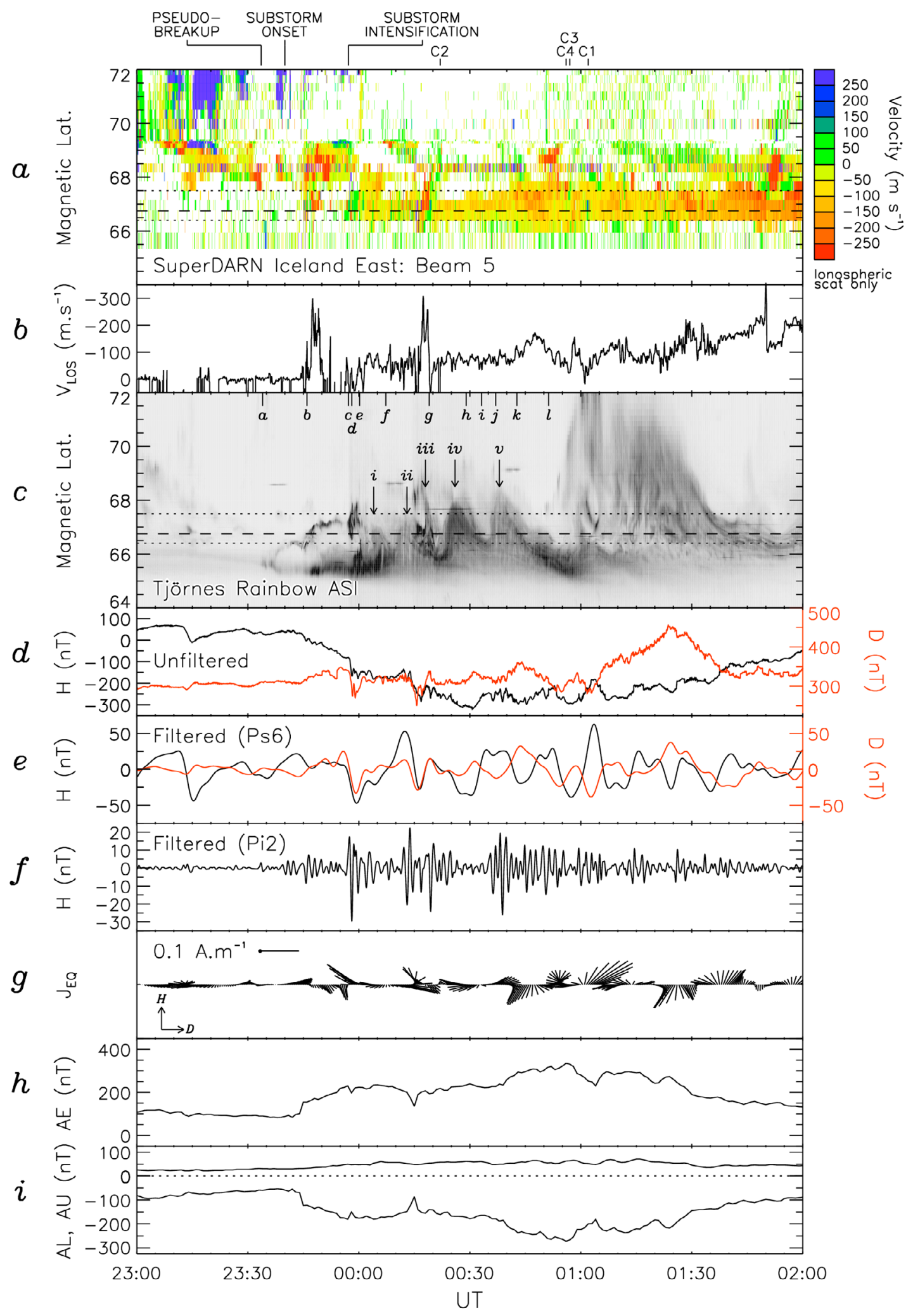

Figure 4

6 of 20 
index (Figure 4h) and both the provisional $A U$ and $A L$ indices from which it is derived (Figure 4i) to indicate global electrojet activity in the auroral zone.

[18] The observations presented in Figure 4 give an overview of the temporal evolution of the auroral features. Before describing these in more detail, it is worthwhile to introduce the spatial evolution of the auroral structures under scrutiny. In Figure 5, we present a summary of the auroral omega bands observed just after midnight on 28 September 2009. Specifically, Figure 5 shows auroral ASI data projected onto a magnetic latitude/magnetic local time coordinate system at $110 \mathrm{~km}$ altitude as if viewed from above. Figures 5a-5l show selected color auroral images as recorded by the Tjörnes ASI between 2334:00 UT and 0051:18 UT with the estimated footprints of the Cluster satellites also indicated. In order to aid comparisons between the time series and spatial data (Figures 4 and 5, respectively), key features are commonly labeled. For example, the specific timings of the 12 all-sky images shown in Figures $5 \mathrm{a}-\mathrm{l}$ are labeled $\mathrm{a}-\mathrm{l}$ in the ASI keogram presented in Figure 4c. Also indicated is the train of auroral omega bands, labeled $\mathrm{i}-\mathrm{v}$ in Figures 4 and 5 . The timing of events introduced in the discussion session, such as key stages of the observed substorm dynamics and the times at which the four Cluster satellites cross the Tjörnes ASI keogram meridian, are also indicated at the top of Figure 4.

[19] At the start of the interval presented in Figure 4 (23 UT on 27 September 2009), the ground-based observations suggest low geomagnetic activity. The $A E$ index was steady at $\sim 100 \mathrm{nT}$ and the Tjörnes ground magnetometer observed a relatively undisturbed magnetic field. At this time, the Tjörnes ASI observed only very faint auroral activity characterized by faint, patchy, and diffuse emission poleward of the zenith and a faint east-west aligned arc slightly equatorward of the zenith. This arc (just visible in the keogram presented in Figure 4) had been present for the preceding hour following earlier substorm activity at 2200 UT. Throughout the first $\sim 45 \mathrm{~min}$ of this interval, the Iceland East SuperDARN radar observed limited and sporadic ionospheric backscatter in the vicinity of the ASI FOV, characterized by persistent bursts of equatorward/westward (positive, color-coded blue) flow poleward of $69^{\circ}$ magnetic latitude that were not associated with auroral emissions. Equatorward of $68^{\circ}$ magnetic latitude, patchy regions of poleward/eastward (negative, color-coded red) flow were observed. Given the relatively short range $(\sim 250 \mathrm{~km})$ at which the SuperDARN Iceland East radar was sounding the auroral oval, it is likely that the radar pulses were being backscattered by $\mathrm{E}$ (rather than $\mathrm{F}$ ) region ionospheric plasma irregularities.
[20] As shown in Figure 3, the IMF was directed southward and duskward throughout this interval. In fact, inspection of a longer time series of upstream data indicates that the IMF $B_{Z}$ component had been southward almost continuously for the preceding $10 \mathrm{~h}$. It is therefore not surprising that the faint arc observed equatorward of the Tjörnes ASI zenith was observed to drift slowly equatorward, consistent with expected motion during the growth phase of a magnetospheric substorm. Inspection of individual ASI images reveals that at 2333:36 UT the faint eastwest aligned arc brightens at the western (duskward) edge of the imager's FOV. This brightening was accompanied by a brief magnetic pulsation in the $\mathrm{Pi} 2$ band and was followed by brightening of the entire arc over the next minute (Figure 5a). In the following $\sim 3 \mathrm{~min}$ a second, faint, arc developed just poleward of the existing arc in the western half of the FOV, extending to just eastward of the zenith (clearly visible in the keogram). However, no significant magnetic disturbances were observed at the Tjörnes station and the global geomagnetic indices do not indicate significant geomagnetic activity at this time.

[21] A further, sustained, burst of Pi2 pulsations was observed at 2340:00 UT and over the next $\sim 5 \mathrm{~min}$, the faint poleward arc brightened and moved poleward. This was accompanied by the onset of a steady decline in the $\mathrm{H}$ component magnetic field recorded at Tjörnes and an enhancement of the $A E$ index (due to a sharp decrease in the value of the $A L$ index). At 2344:30 UT, a few minutes after the Pi2 pulsations began, the poleward arc brightened significantly (Figure 5b). As the arc brightened, a sudden increase in the amount of $E$ region ionospheric backscatter was observed in the region of the ASI zenith by the Iceland East radar, with the flow directed strongly $\left(>200 \mathrm{~m} \mathrm{~s}^{-1}\right)$ away from the radar (poleward and eastward) for the next $5 \mathrm{~min}$.

[22] After remaining steady for $\sim 13$ min after 2344:30 UT, the poleward arc brightened dramatically and expanded, starting at 2357:12 UT (Figures 5c and 5d). This intensification in auroral emissions was accompanied by a (colocated) sharp increase in the northward and eastward ionospheric velocity observed in Beam 5 of the Iceland East radar, a further intensification in $\mathrm{Pi} 2$ pulsation amplitude and sharp disturbances in the $\mathrm{H}$ and $\mathrm{D}$ components of the ground magnetic observed at Tjörnes. The auroral breakup and poleward expansion continued over the following minutes (Figure 5e).

[23] During the next $\sim 45$ min a series of undulations or torches were observed propagating eastward through the ASI field of view. Five examples (numbered $i-v$ ), indicated in the keogram presented in Figure 4, correspond to omega-

Figure 4. An overview of ground-based data used in this study. (a) Line-of-sight ionospheric Doppler velocity measured by the SuperDARN Iceland East radar; (b) average line-of-sight velocity extracted from a subset of radar range gates; (c) an inverse gray scale keogram of auroral activity extracted from the magnetic meridian passing through the Tjörnes Rainbow ASI; (d) unfiltered H (black) and D (red) component ground magnetometer measurements; (e) H (black) and D (red) component ground magnetometer measurements band-pass filtered to reveal pulsations in the Ps6 band (4-40 min periods); (f) $\mathrm{H}$ component ground magnetometer measurements band-pass filtered to reveal pulsations in the Pi2 band (40-150 s periods); (g) equivalent current vectors derived from ground magnetometer data; (h) variations in the (provisional) $A E$ index; and (i) variations in the (provisional) $A U$ and $A L$ indices. Auroral omega bands discussed in the text are labeled $\mathrm{i}-\mathrm{v}$. The timings of ASI frames presented in Figure 5 are labeled $\mathrm{a}-1$. 


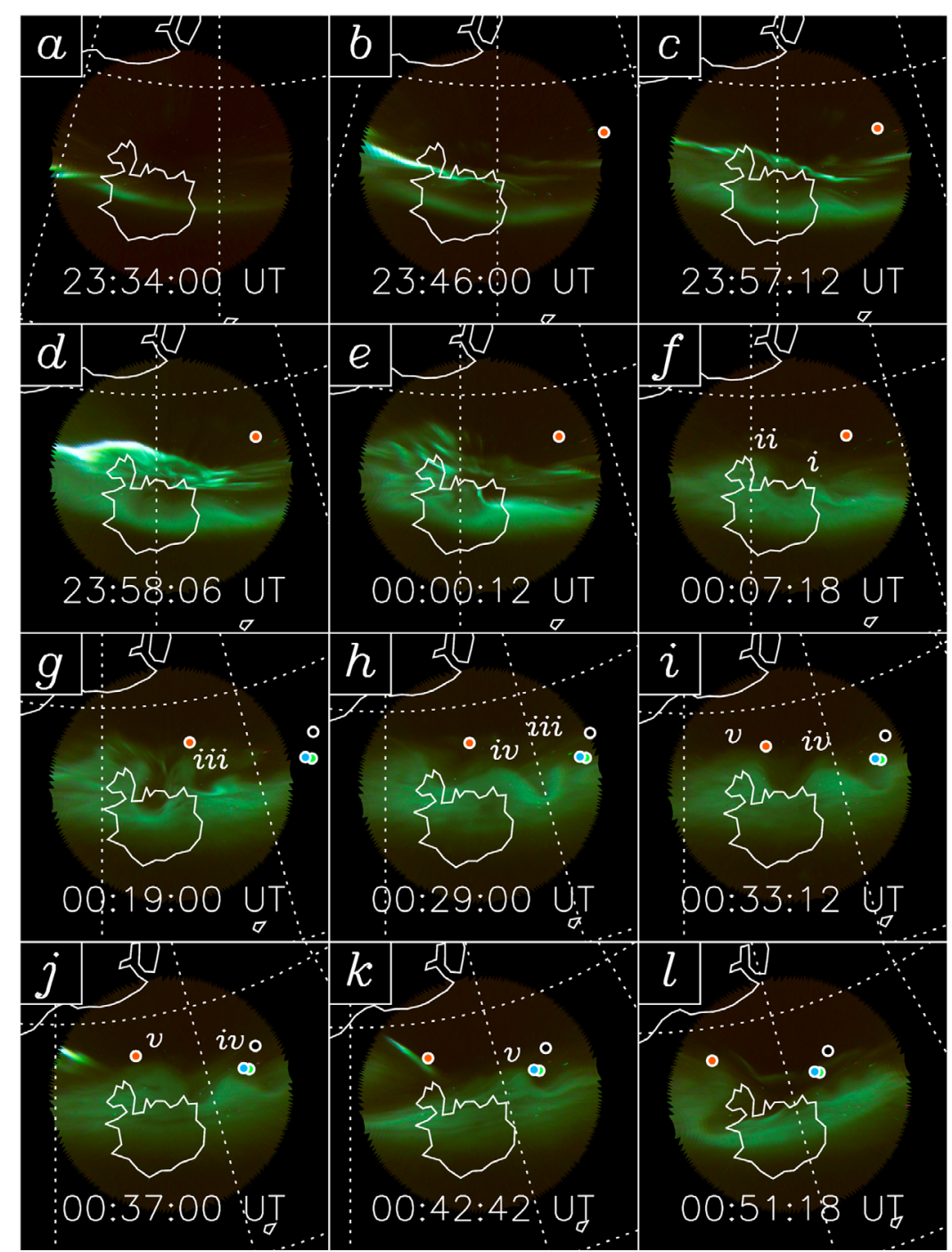

Figure 5. All-sky images recorded by the Tjörnes Rainbow imager during the passage of auroral omega bands. The images are projected onto a magnetic latitude/magnetic local time grid at an altitude of $110 \mathrm{~km}$. (a) The dotted vertical line corresponds to the 0000 MLT meridian, with other MLT meridians indicated at $1 \mathrm{~h}$ intervals. In Figures 5b-51, the ASI remains at the center, and these grid lines move owing to the advancing universal time. The curved dotted lines indicate the $70^{\circ} \mathrm{N}$ and $60^{\circ} \mathrm{N}$ parallels of magnetic latitude. Projected at an emission altitude of $110 \mathrm{~km}$, the edge of the circular field of view $\left(10^{\circ}\right.$ above the local horizon at the ASI site) corresponds to a ground range of approximately $500 \mathrm{~km}$ from the ASI. The magnetic footprints at $110 \mathrm{~km}$ of the four Cluster satellites are also overlaid, color-coded as in Figure 2. Auroral omega bands discussed in the text are labeled $\mathrm{i}-\mathrm{v}$.

shaped torches on the poleward boundary of the visible auroral emission in Figures $5 \mathrm{f}-51$.

[24] Throughout the period when omega bands were transiting the ASI field of view, strong Ps6 pulsations were recorded by the Tjörnes magnetometer. Although the phasing of $H$ and $D$ component fluctuations varied, after $\sim 0030$ UT, the two components were approximately $180^{\circ}$ out of phase. When plotted as ionospheric equivalent current vectors, these fluctuations manifest as clockwise rotations in the equivalent current direction. At $\sim 0100 \mathrm{UT}$, following the peak in the $A E$ index (due to a minimum in the $A L$ index), auroral emissions underwent another sudden poleward expansion. For the next $\sim 45 \mathrm{~min}$, multiple pulsating arclets filled the ASI field of view.

\subsection{Magnetospheric Observations}

[25] As indicated in Figure 5, the Cluster quartet entered the Tjörnes ASI field of view from the eastern horizon (moving east to west) when the torch-like auroral features were moving west to east over the ASI. We will therefore examine in situ field and particle measurements from the satellites as they transit the Earth's magnetic tail.

[26] Figure 6 presents field and particle measurements from Cluster 3 between 2300 and 0200 UT. At this stage, we present detailed data from one satellite only, as the measurements are similar across the Cluster quartet. Multisatellite measurements are presented in section 4. Figure 6 (first to third panels) show standard energy-time spectro- 

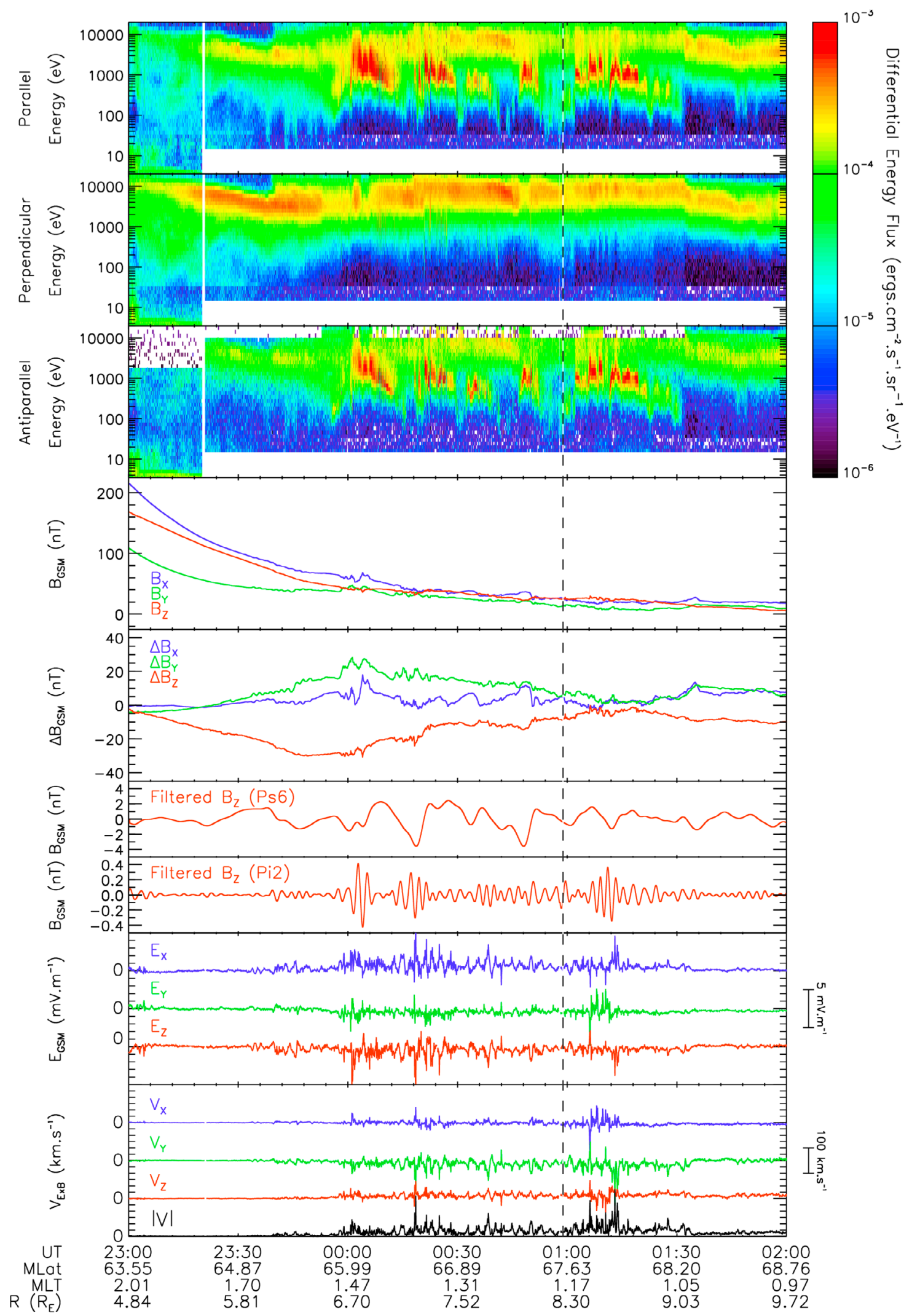

Figure 6 
grams of electron differential energy flux in directions parallel, perpendicular, and antiparallel to the local magnetic field. These spectra include data from both the high- and low-energy electron analyzers that constitute the PEACE instrument (HEEA and LEEA, respectively) and have temporal resolution equal to the satellite's spin period $(\sim 4 \mathrm{~s})$.

[27] Figure 6 (fourth to seventh panels) present corresponding magnetic field measurements from the Cluster 3 FGM experiment. Although these three-component data are analyzed at a resolution of 5 vectors per second, they have been smoothed by application of a running average window of length equivalent to the satellite spin period to remove high-frequency fluctuations. Figure 6 shows the $B_{X}, B_{Y}$ and $B_{Z}$ magnetic field components in the GSM coordinate system; the residual magnetic field components $\left(\Delta B_{X}, \Delta B_{Y}\right.$, and $\Delta B_{Z}$ ) after subtraction of the (T01) model magnetic field from the observed field; $B_{Z}$ component measurements, band-pass filtered to reveal oscillations in the Ps6 pulsation range; $B_{Z}$ component measurements, band-pass filtered to reveal oscillations in the $\mathrm{Pi} 2$ pulsation range.

[28] Figure 6 (eighth and ninth panels) present the electric field measurements made by the Cluster $3 \mathrm{EFW}$ instrument and the $\mathbf{E} \times \mathbf{B}$ plasma velocity $\left(\mathbf{V}_{E \times B}\right)$ based on combined magnetic and electric field measurements. All data are presented according to a common universal time axis that is also labeled in terms of the magnetic latitude and magnetic latitude of the satellite's T01 footprint and its radial distance from the Earth. The time at which the Cluster 3 satellite crossed the central magnetic meridian of the Tjörnes ASI is indicated by a dashed vertical line.

[29] At 2300 UT (the start of the interval presented in Figure 6), Cluster 3, located $\sim 5 R_{E}$ from the Earth, was moving southward toward the equatorial plane in the 2 MLT sector. Over the next $3 \mathrm{~h}$, the satellite's elliptical orbit took it southward and slightly dawnward, traversing the inner edge of the plasma sheet and doubling its radial distance from the Earth by 0200 UT.

[30] Throughout the interval, the Cluster 3 PEACE electron detectors observed a population of 1 to $10 \mathrm{keV}$ electron in the field parallel, perpendicular and antiparallel directions (clearest in the field perpendicular energy-time spectrogram). We note that high-energy field antiparallel measurements from the PEACE HEEA sensor are not available throughout. Starting at 2355 UT, short-lived bursts of electrons with dispersed energy signatures in the $0.1-10 \mathrm{keV}$ range were observed in the field parallel and antiparallel directions. These electron bursts, each lasting between 5 and $15 \mathrm{~min}$, were observed intermittently until $\sim 0130$ UT.
[31] Magnetic field measurements made by Cluster 3 (Figure 6) indicate the expected decline in magnetic field strength as the satellite receded from the Earth. The residual magnetic field $(\Delta B)$, calculated by subtracting the timeand position-dependent T01 model field (parameterized by upstream data from THEMIS $\mathrm{C}$, as described above), indicates the perturbations from the expected magnetic field. Throughout the $3 \mathrm{~h}$ interval presented in Figure 6, the $\Delta B_{X}$ component was relatively small (typically within the $0-10 \mathrm{nT}$ range) with the largest ( $\sim 15 \mathrm{nT})$ residuals occurring during Cluster 3's encounters with the transient field parallel/ antiparallel electron fluxes. The general trend in the $\Delta B_{X}$ component (increasing from 2300 to $0000 \mathrm{UT}$, decreasing from 0000 to $0100 \mathrm{UT}$, and increasing again from 0100 to 0200 UT with significant perturbations as the satellite was engulfed by energetic electrons) was repeated in the $\Delta B_{Y}$ and $\Delta B_{Z}$ components. Overall, $\Delta B_{X}$, the smallest residual, was positive (suggesting that the observed $B_{X}$ was greater than predicted); $\Delta B_{Y}$ was generally larger and positive (suggesting that the observed $B_{Y}$ was greater than predicted); and $\Delta B_{Z}$ was the largest residual and negative (suggesting that the observed $B_{Z}$ was smaller than predicted). We note that the largest residual fields (observed during several particle encounters or more generally after $\sim 0115$ UT) approached $\sim 50 \%$ of the observed magnetic field. The residual magnetic field data presented in Figure 6 also include periodic oscillations. When band-pass filtered with appropriate high- and low-frequency cutoff filters, the magnetic field measurements from Cluster revealed Ps6 and $\mathrm{Pi} 2$ pulsation activity, broadly corresponding to the wave activity observed by ground-based magnetometers (we note that for reasons of clarity, Figure 6 only presents band-pass filtered $B_{Z}$ component data, but equivalent activity is observed in all three magnetic field components).

[32] Shortly after 2330 UT, the EFW instrument began to record an increasingly variable electric field. The variability and strength of this field were generally related to the parallel/antiparallel electron fluxes and accompanying magnetic disturbances; that is, the peak electric fields were observed at times when the parallel/antiparallel electron fluxes were enhanced from the background level. Analysis of the electric field data between 2330 and 0130 UT revealed a dominant, $150 \mathrm{~s}$ oscillation in all three components. In the magnetic field data, perturbations with $\sim 900$ s periodicity dominate, with lower power peaks in the frequency spectrum corresponding to 450,300 and 150 s periodicities. When combined to estimate the local plasma velocity, these measurements reveal that $\mathbf{V}_{E \times B}$ was generally largest at

Figure 6. Electron flux and magnetic field measurements from the Cluster 3 satellites. The first to third panels present PEACE energy-time spectrograms of differential energy flux (DEF) parallel, perpendicular and antiparallel to the local magnetic field. DEF is color-coded according to the color bar on the right side. The fourth and fifth panels show the GSM magnetic field components measured by the FGM experiment $\left(\mathrm{B}_{G S M}\right)$ and the residual magnetic field components $\left(\Delta B_{G S M}\right)$ that remain following subtraction of the local magnetic field predicted by the T01 magnetospheric field model. The sixth and seventh panels show $B_{Z}$ component data, band-pass filtered to reveal pulsations in the Ps6 and Pi2 frequency ranges, respectively. The eighth and ninth panels present electric field measurements from the EFW experiment and the resulting $\mathrm{V}_{E \times B}$, respectively. All panels are plotted according to a common universal time axis. The magnetic latitude and local time of the satellite's footprint, as well as its radial displacement from the center of the Earth, are also indicated. The time at which the satellite's footprint crossed the Tjörnes ASI MLT meridian is indicated by a dashed vertical line. 
times when high parallel/antiparallel electron fluxes in the $\sim \mathrm{keV}$ energy range were observed.

\section{Discussion}

[33] In section 3, we introduced ground-based observations of omega bands propagating eastward along the poleward boundary of an east-west aligned auroral arc. In this section, we examine the bands' structure and evolution in the context of the geomagnetic and magnetospheric conditions that prevailed at the time.

\subsection{Ionospheric Electrodynamics}

[34] The auroral and magnetic measurements presented in Figure 4 clearly indicate substorm activity in the late hours of 27 September 2009. In the hour prior to 0000 UT on the 28 September, typical growth phase conditions were observed during a period of steady southward IMF. Specifically, a quiet auroral arc was observed to drift equatorward for an hour or more before brightening at 2333:36 UT. Although it occurred at the same time as a weak ( $\sim 5 \mathrm{nT}$ peak-to-peak amplitude), short-lived ( $<3$ min duration) $\mathrm{Pi} 2$ pulsation, and was followed by a faint poleward drifting arc, this auroral brightening was not accompanied by significant local or global magnetic disturbances. However, the subsequent burst of Pi2 activity, starting at 2240:00 UT, was followed by the brightening and northward expansion of the poleward auroral arc. The auroral dynamics were accompanied by a steady decrease in the $\mathrm{H}$ component of the magnetic field, indicating a strengthening of the overhead westward electrojet, and a sharp increase in the $A E$ index, indicating a global intensification of the auroral zone electrojets. After continued growth of the $A E$ index, auroral dynamics and $\mathrm{Pi} 2$ activity increased considerably at 2357:12 UT and ground magnetometer data indicated a sudden deepening of the observed $\mathrm{H}$ component negative bay.

[35] We interpret these observations as evidence of multistage substorm activity. We suggest that the first stage, starting at 2333:36 UT, was a pseudobeakup that did not evolve into a full substorm. However, the second stage, starting with the Pi2 pulsations observed at 2340:00 UT, developed into a full substorm and marked the onset of the expansion phase. This expansion phase was characterized by poleward moving auroral structures, the brightening and broadening of an equatorward arc and enhanced electrojet currents. The third stage comprised a sharp intensification of the substorm expansion phase at 2357:12 UT, leading to increased currents flowing overhead and a sudden increase in auroral dynamics. The inferred timing of these three stages, labeled "psuedobreakup", "substorm onset" and "substorm intensification", are indicated at the top of Figure 4. Inspection of individual auroral images (Figures 5a-5e) indicates that the substorm expansion phase onset was initiated in the premidnight MLT sector, westward (duskward) of the Tjörnes ASI. This location is consistent with the typical premidnight location of the auroral brightenings associated with expansion phase onset [e.g., Frey et al., 2004].

[36] Within a few minutes of the substorm expansion phase onset and subsequent intensification, auroral omega bands were observed propagating eastward (dawnward) from the onset region. Typically, the auroral structures extended $\sim 200 \mathrm{~km}$ in the north-south direction and $\sim 150 \mathrm{~km}$ in the east-west direction. Based upon their transit time across the ASI field of view, their eastward propagation speed was estimated to be $\sim 400 \mathrm{~m} \mathrm{~s}^{-1}$. At the time these structures were observed, the poleward edge of the main auroral arc was located overhead the Tjörnes ASI such that the omega-shaped torches extended to the north of the zenith (and the northern coastline of Iceland). Nevertheless, the Tjörnes magnetometer (which integrates over a region spanning several hundred kilometers) recorded Ps6 pulsations during the passage of the omega bands. When plotted as ionospheric equivalent currents, these magnetic perturbations are consistent with the passage of vortical ionospheric Hall currents associated with upward/downward field-aligned currents over the magnetometer [Lühr and Schlegel, 1994; Wild et al., 2000].

[37] The average line-of-sight ionospheric flow velocity in the main band of radar backscatter in beam 5 (the region between the dashed lines in the radar/ASI panels of Figure 4) was generally directed away from the radar. Given the orientation of the beam (northward and eastward), the precise direction of this flow cannot be resolved unambiguously. However, the average LOS velocity increased rapidly from zero at the beginning of the interval (when limited backscattered signals were available) to over $200 \mathrm{~m} \mathrm{~s}^{-1}$ away from the radar during the flow burst, which coincided with the substorm expansion phase onset. A second high-speed flow burst between 0015 and 0020 UT corresponded to a bright auroral transient that formed simultaneously with omega band iii in Figure 4; otherwise, there is no clear correlation between the relatively steady $\sim 100 \mathrm{~m} \mathrm{~s}^{-1}$ flow away from the radar and omega band passage. In the case of the omega bands labeled $\mathrm{i}$ and iii, there is some evidence of backscatter feature recession from the radar (migration to increasing latitudes) as the auroral structures crossed the ASI meridian.

[38] The enhanced background flow observed is consistent with large-scale convection development during the substorm. No direct relationship with the omega band structures is expected [e.g., Grocott et al., 2002]. On the other hand, Grocott et al. [2004] observed the flow signature of a substorm pseudobreakup and concurrent bursty bulk flow in the magnetosphere. In this case the flow signature was of a more vortical nature, being related to the associated field-aligned current system. The similarly vortical nature of the omega band current system could therefore explain the poleward component of the flow features observed in this case.

\subsection{Magnetic Field Line Mapping}

[39] The Cluster 3 field and plasma observations introduced in Figure 6 indicated structured particle fluxes in the magnetotail when the suite of ground-based instruments observed the eastward propagating auroral omega bands. In order to investigate any possible link, we present field parallel electron fluxes observed by all four Cluster satellites (Figure 7) and indicate the footprint location of each satellite relative to the auroral observations discussed above. The latitudinal profiles of the Cluster footprints are overlaid on the ASI keogram and SuperDARN velocity panels included in Figure 4. In terms of the motion of the footprint during the interval under study, the slightly duskward orbital motion of the satellite is less significant that the dawnward 

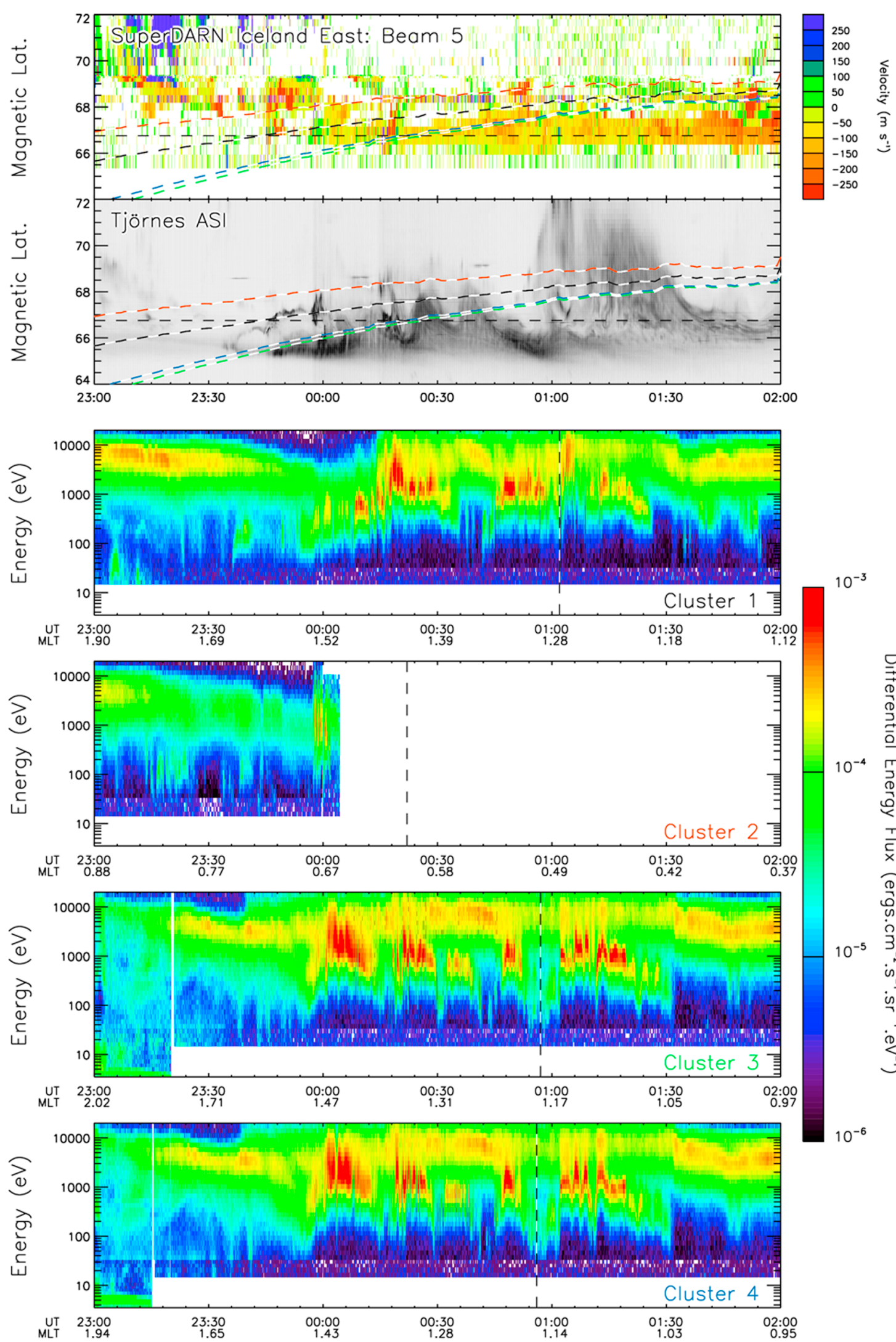

Figure 7 
rotation of the Earth, which steadily brings the ASI FOV under the Cluster magnetic footprints. As indicated in Figures 1, 2 and 5, Cluster 2 (red) was located farthest from the Earth and at the earliest MLT of the four satellites. Its footprint was therefore located farther west and at the highest magnetic latitude of the four satellites. Cluster 1 (black), 3 (green) and 4 (blue) are located at similar magnetic local times, with 3 and 4 slightly closer to the Earth. These three satellites have magnetic footprints at similar magnetic local times (within $0.2 \mathrm{~h}$ of MLT); Cluster 1 's footprint is located $\sim 1^{\circ}$ of magnetic latitude poleward of the Cluster 3 and 4 footprints at the start of the interval (reducing to $\sim 0.5^{\circ}$ by the end).

[40] As discussed above, comparisons between the modeled and observed magnetic field at the location of Cluster 3 indicate that the T01 model (exploited to estimate the Cluster magnetic footprints) did not fully reflect the actual magnetospheric field configuration during the interval of interest. Residual magnetic fields suggest that the actual field was more stretched (with larger $B_{X}$ and $B_{Y}$, but smaller $B_{Z}$ ) than predicted for the T01 model. The sense and temporal evolution of these residuals were consistent with substorm activity inferred from ground-based observations. The residual fields increased during the growth phase as the tail field became increasingly stretched. They subsequently decreased as the tail field dipolarized during the expansion phase, with brief disturbances due to the passage of bursts of energetic electrons moving parallel and antiparallel to the local field line.

[41] As might be expected, this suggests that the reliability of the magnetic field model used is uncertain during the late growth phase and early expansion phase of the substorm. Nevertheless, the model is required to estimate the satellite footprints in the ionosphere. Uncertainties are expected to be greatest during the Cluster 2 passage through the ASI field of view in the early part of expansion phase. However, for operational reasons, electron measurements are only available from Cluster 2 until just after midnight on 28 September, before it had passed over the Tjörnes ASI site. The estimated Cluster 2 footprint (with questionable reliability) was poleward (tailward) of the auroral omega bands and, with the exception of brief, glancing encounters with the poleward boundary of omega band torches, did not traverse auroral structures until the latter part of the interval when the aurora had expanded poleward to fill the ASI field of view. However, the remaining Cluster satellites $(1,3$, and 4 ) were recording throughout the conjunction with the ground-based experiments, and magnetic field line mapping from the magnetosphere to the ionosphere is essential to this study.

[42] To estimate the level of uncertainty in field line mapping during overflights of the remaining Cluster satellites spacecraft through the Tjörnes ASI, the T01 mapping employed in this study has been compared to equivalent mapping using the Tsyganenko 1996 (T96) model [Tsyganenko, 1995]. Although it does not yield definitive mapping errors, this benchmarking reveals the extent to which the field line mapping depends on the specific magnetospheric field model selected. We therefore recompute the Cluster footprints using the T96 model using identical input parameters and compare the results to those from the T01 model. Between 2200 and 0200 UT, the average displacement between the Cluster footprints estimated by the two models is $\sim 0.5$ degrees of magnetic latitude and $\sim 0.25$ degrees of magnetic longitude (approximately $1 \mathrm{~min}$ of magnetic local time). In the ionosphere (at $110 \mathrm{~km}$ altitude) this corresponds to a distance of approximately $50 \mathrm{~km}$. At 0100 UT, when Cluster 1, 3 and 4 were in the vicinity of the Tjörnes ASI meridian, the westward horizontal speed of the footprints at $110 \mathrm{~km}$ altitude was $\sim 0.25 \mathrm{~km} \mathrm{~s}^{-1}$, irrespective of the magnetospheric model selected. As such, the $\sim 0.25^{\circ}$ longitudinal difference in the T01 and T96 footprints corresponds to a difference in arrival time at a specific magnetic meridian of $\sim 45 \mathrm{~s}$, with the T01 footprints consistently located slightly poleward and westward of the T96 footprints at any given universal time. We therefore conclude that although the two Tsyganenko field models predict slightly different satellite footprint locations (for a given set of input parameters), the discrepancy is not significant. Ultimately, the choice of magnetospheric model is not critical to the analysis that follows and the selection of the T01 (inner magnetosphere) model is appropriate.

\subsection{Magnetosphere-Ionosphere Coupling}

[43] Although the footprints of the Cluster 1, 3 and 4 satellites were at latitudes comparable to the omega bands, they did not encounter the eastward moving auroral structures until after $\sim 0019$ UT, when residual magnetic fields at the satellites were much reduced compared to those encountered by Cluster 2 (some 30 min earlier). We therefore use the estimated footprints to compare in situ measurements at the remaining satellites and the auroral luminosity at each satellite's footprint. Figure 8 presents this comparison for Clusters 1, 3 and 4 .

[44] The brightness in Figure 8 is at the satellite's Northern Hemisphere magnetic footprint. To take into account small uncertainties in the magnetic field mapping, the auroral brightness at each time has been calculated by averaging over a $25 \mathrm{~km}$ radius area centered on the estimated footprint position. The diameter of the averaging region is therefore comparable to the displacement found between the footprints yielded by the T01 and T96 magnetic field models in the benchmarking exercise described above. Figure 8 shows the time series of auroral luminosity averaged around each footprint as the satellite overflew the Tjörnes ASI. The black trace indicating auroral luminosity is dotted when the satellite footprint is within $10^{\circ}$ of elevation

Figure 7. Field-parallel electron differential energy fluxes measured at Cluster 1, 2, 3 and 4 (third to sixth panels). Fluxes are color-coded as a function of universal time and particle energy according to the color bar on the right side. To compare the in situ measurements with ionosphere observations, the first and second panels show the SuperDARN and all-sky imager data presented in Figure 4 on which each satellite's magnetic footprint has been indicated by a colored dashed line ( $\mathrm{C} 1$, blank/white; $\mathrm{C} 2$, red/white; $\mathrm{C} 3$, green/white; $\mathrm{C} 4$, blue/white). Furthermore, each electron energy-time spectrogram is annotated with the MLT of that satellite's footprint (horizontal axis) and the time at which the footprint crosses the magnetic meridian of the Tjörnes ASI (dashed vertical line). 

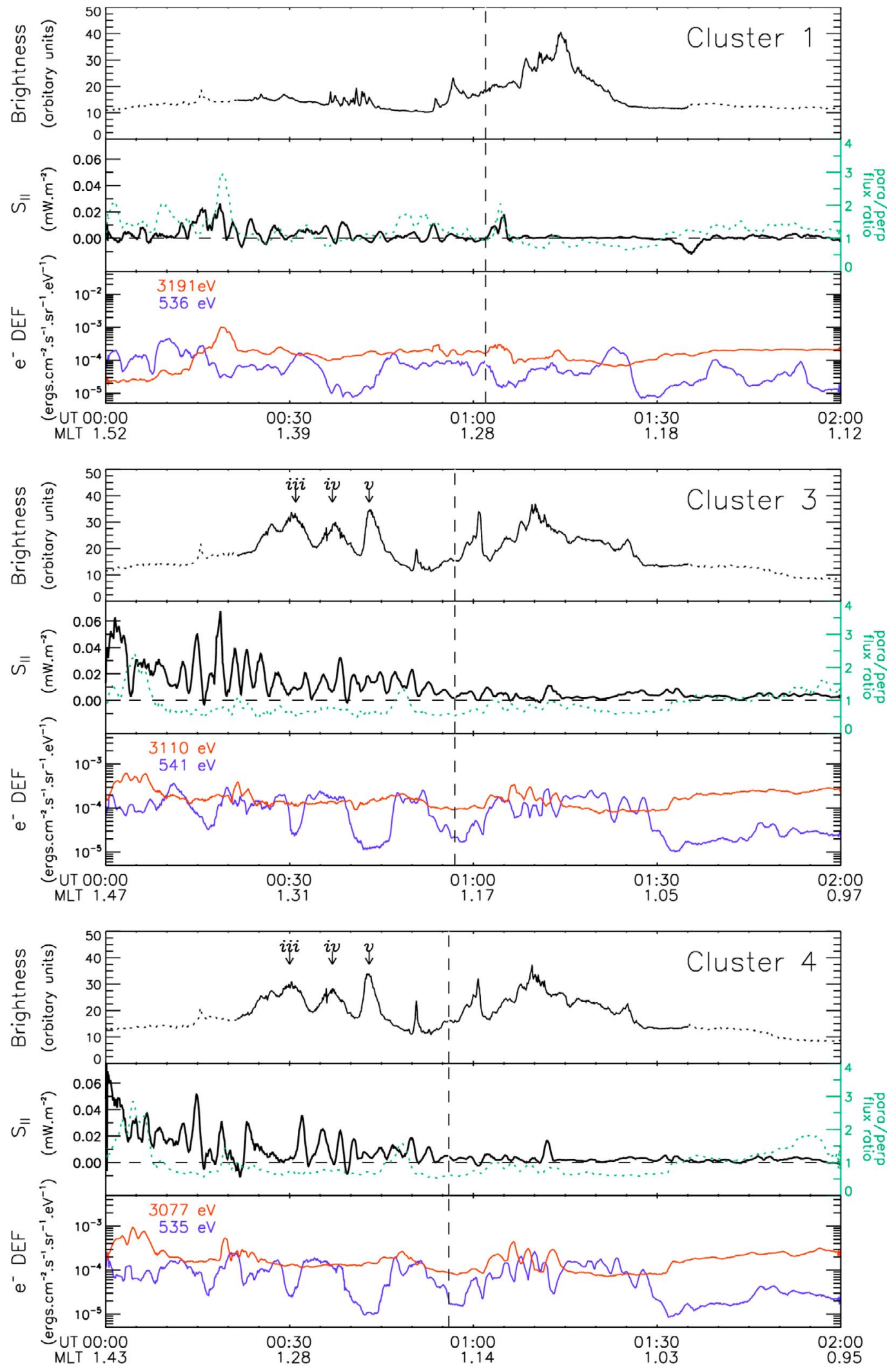

Figure 8 
from the local horizon (where uncertainties in the all-sky projection are most sensitive to the assumed emission altitude) and solid where the footprint is $>10^{\circ}$ from the horizon.

[45] $S_{\|}$in Figure 8 is the Poynting flux and integrated electron energy flux based on in situ plasma measurements. Electric and magnetic field measurements from the Cluster EFW and FGM instruments have been used to calculate field-aligned Poynting flux, $S_{\|}$, at the satellite location:

$$
S_{\|}=\mathbf{S} \cdot \frac{\mathbf{B}}{|\mathbf{B}|}
$$

where $\mathbf{B}$ is the local magnetic field and $\mathbf{S}$ is the Poynting vector. As described by Keiling et al. [2002], to calculate the Poynting flux vector, perturbation electric $(\delta \mathbf{E})$ and magnetic $(\delta \mathbf{B})$ fields are combined; thus,

$$
\mathbf{S}=\frac{1}{\mu_{0}} \delta \mathbf{E} \times \delta \mathbf{B}
$$

The field-aligned Poynting flux, $S_{\|}$, indicated by the black trace, accounts for the transport of energy along the background magnetic field. The ratio of the integrated electron energy fluxes parallel and perpendicular to the local magnetic field is shown for comparison (dotted green trace). This is computed by summing the differential energy flux (DEF) of over all energy ranges covered by the PEACE instrument in the pitch angle bin containing the local field, then dividing by the equivalent integrated energy flux from the orthogonal pitch angle bin. Values of this ratio $>1$ indicate that the field-aligned electron energy flux exceeds the field-perpendicular energy flux. Values $<1$ indicate that the field-perpendicular electron energy flux is greater.

[46] The $e^{-}$DEF in Figure 8 is the field-aligned differential energy flux (DEF) observed by the PEACE instrument in two representative electron energy ranges. Although the exact energy bins differ very slightly between the PEACE sensors on each satellite, comparable energy levels have been selected in each case. Electron DEF in a $\sim 100 \mathrm{eV}$ wide energy bin centered on approximately $500 \mathrm{eV}$ is indicated by the blue trace, and DEF in a $\sim 700 \mathrm{eV}$ wide energy bin centered on approximately $3 \mathrm{keV}$ range is shown by the red trace. The central energies of each bin are indicated in Figure 8.

[47] The footprints of the Cluster 1,3 and 4 satellites entered the "central" portion of the Tjörnes ASI field of view ( $>10^{\circ}$ from the horizon) at $0025 \mathrm{UT}, 0022 \mathrm{UT}$ and 0019 UT, respectively. By the time they had traversed the eastern half of the field of view and arrived at the central meridian of the ASI (indicated by dashed vertical lines at 0102 UT (Cluster 1), 0057 UT (Cluster 3) and 0056 UT
(Cluster 4) in Figure 8), a series of omega bands had been encountered. Examination of individual ASI frames indicates that Cluster 3 and 4 cut though the omega bands labeled as iii, iv, and $\mathrm{v}$ in Figures 4 and 5 with corresponding peaks in the brightness traces for these satellites (labeled iii-V in Figure 8). We note that the peak at 0051 UT in the Cluster 3 and 4 brightness traces corresponded to an encounter with a narrow arc that briefly formed poleward of the main arc (Figure 5l) and not an omega band attached to the main arc. Cluster 1, at slightly higher latitude, did not pass though any omega band structures.

[48] As discussed above, the Cluster 3 electron energytime spectra presented in Figure 6 reveal a high-energy (1$10 \mathrm{keV}$ ) electron population in the magnetotail, evident at all pitch angles. In addition, short-lived enhancements in the differential energy flux carried by electrons in the lower, $0.1-$ $1 \mathrm{keV}$ range in the field parallel and antiparallel directions were observed, starting at $\sim 0000$ UT. Although Figure 6 presents measurements from Cluster 3 only, similar structures were also observed at Cluster 1 and 4 (no Cluster 2 electron data were available after 0005 UT). These data indicate a large differential energy flux of high-energy electrons during the interval in which auroral omega bands were observed. The high-energy population has strongest fluxes perpendicular to the magnetic field, suggesting that it is a largely trapped population. The angular resolution of the PEACE instrument is $15^{\circ}$ in the plane parallel to the satellite spin axis and $11.25^{\circ}$ in the plane perpendicular to the spin axis. Since the loss cone of precipitating electrons is likely to be $\sim 3^{\circ}$, the field-aligned energy-time spectra will contain a mixture of precipitating and trapped electrons. Conversely, the lower-energy electrons were only observed in the fieldaligned (parallel and antiparallel) sensor, suggesting that the electrons observed in the parallel pitch angle bin were more likely to precipitate into the auroral zone, with the remainder of that population mirroring at lower altitudes and being observed at antiparallel pitch angles.

[49] The auroral brightness time series for the Cluster 3 footprint shown in Figure 8 includes the clear signatures of three omega bands. These features, which are labeled iii-iv, and $\mathrm{v}$, correspond to similarly labeled features in Figure 5. Note that these features move eastward through Cluster 3's footprint between 0025 and $0050 \mathrm{UT}$, while the footprint is in the eastern portion of the FOV (i.e., prior to the transit of the satellite through the ASI's magnetic local time meridian, indicated by the dashed vertical line in Figure 8). Between 0000 and 0100 UT (corresponding to the satellite's passage through this eastern portion of the imager), the field-aligned Poynting flux exhibits the same $\sim 150$ s variability observed in the underlying electric field data, with localized peaks in

Figure 8. Comparisons between in situ field and plasma measurements at the Cluster satellites and auroral brightness at the ionospheric footprint (Cluster 1, 3, and 4). For brightness plots the black trace shows the auroral brightness (arbitrary units) at the location of the satellite's footprint. The brightness trace is dotted where the footprint is within $10^{\circ}$ of the local horizon at the Tjörnes ASI, but is presented as a solid line where the footprint lies more than $10^{\circ}$ from the imager's local horizon. The field-aligned Poynting flux $S_{\|}$(derived from electric and magnetic field measurements) is shown in black, and the ratio of field-parallel to field-perpendicular integrated electron flux is shown in dotted green (according to the scale on the right). The blue trace shows the DEF of electrons in the PEACE $500 \mathrm{eV}$ energy bin; the red trace shows the DEF of electrons in the $3 \mathrm{keV}$ energy bin. All panels are plotted according to a common universal time axis and are annotated with the MLT of that satellite's footprint and the time at which the footprint crosses the magnetic meridian of the Tjörnes ASI (dashed vertical line). Auroral omega bands discussed in the text are labeled iii-v. 
the envelope centered at 0002 and 0018 UT. The parallelto-perpendicular electron energy flux ratio was typically less than unity (indicating that electron energy flux in the fieldperpendicular direction exceeded that in the field-parallel direction) and displayed similar short-period variability, with peaks at $0006 \mathrm{UT}, 0022 \mathrm{UT}$ and $0048 \mathrm{UT}$. The differential energy flux of electrons in the $\sim 3 \mathrm{keV}$ energy range remained relatively constant throughout the interval, although modest (up to $\sim 50 \%$ ) variations were observed (such as between 0000 and 0010 UT). In contrast, the differential energy flux carried by low-energy electrons ( $\sim 500 \mathrm{eV}$ shown in Figure 8$)$ varied by more than an order of magnitude throughout the interval, with the higher-flux intervals corresponding to the bursts of parallel/antiparallel electrons shown in the PEACE electron spectra (Figure 6).

[50] As the Cluster 3 footprint approached the Tjörnes ASI central meridian at 0057 UT, the aurora expanded poleward (as shown in the keogram in Figure 6). Consequently, as the satellite traversed the western half of the imager's FOV, it overflew dynamic auroral structures including, for example, a spatially localized brightening at 0101 UT, but no additional distinct omega bands. The auroral brightness at the footprint was high and variable over the following half hour until the satellite left the FOV. The field-aligned Poynting flux estimated from electric and magnetic field data was markedly lower during this interval than during the preceding hour, but fluctuations in the ratio of parallel-to-perpendicular integrated electron energy flux continued, driven by bursts of both high- and low-energy field-aligned electron flux. After $\sim 0130$, the lower-energy electron DEF declined sharply, whereas the higher-energy electron DEF increased very slightly.

[51] To summarize the relevant Cluster 3 measurements, the calculated field-aligned Poynting flux varied rapidly throughout the interval when the satellite was conjugate to omega bands iii-v. The energy flux ratio between electrons moving in the field-parallel and field-perpendicular directions indicates that more flux was included in the latter, but the ratio fluctuated upward several times during the 0025 to 0100 UT interval in which the three omega bands were observed. Given the generally steady field-perpendicular differential energy flux observed during this period (as shown in Figure 6), this increase in the field parallel/ perpendicular ratio indicates enhancements in the fieldparallel direction. An exception is the sharp increase in the flux ratio at 0048 UT due to a simultaneous increase in the field-parallel flux and a decrease in the field perpendicular flux (clearly apparent in Figure 6). Scrutiny of individual electron energy channels of the PEACE instrument reveals that this increase in the amount of field-parallel differential energy flux is associated with large (factor of 10) enhancements in the flux of lower-energy electrons (illustrative $\sim 500 \mathrm{eV}$ electrons shown in Figure 8).

[52] Any one-to-one correspondence between the auroral omega bands at the footprint of the Cluster 3 satellite and field and plasma measurements is not obvious. The fluctuations in Poynting flux indicate variable transport of energy along the background magnetic field toward the ionosphere, and the particle data indicate intervals of increased electron energy flux in the field-parallel direction, mainly carried by low-energy electrons $(<1 \mathrm{keV})$. There is a suggestion of localized peaks in the flux ratio as the satellite passed over omega bands iii-v, but these are by no means the greatest flux ratios observed. The large peak in the flux ratio at 0048 UT follows omega band $\mathrm{v}$ by $\sim 4 \mathrm{~min}$ but precedes a short-duration enhancement in auroral brightness at 0051 UT. As noted previously, inspection of individual ASI frames reveals that this enhancement is a due to a narrow $(\sim 10 \mathrm{~km})$, faint, and short-lived $(\sim 2 \mathrm{~min})$ arc that appeared poleward of the main region of auroral emission (as shown in Figure 51).

[53] Perhaps unsurprisingly (given the proximity of the satellites and their footprints), the Cluster 4 field and plasma measurements are very similar to those from Cluster 3 . The satellites encountered the three omega bands (iii-v) prior to crossing the central meridian of the Tjörnes ASI (i.e., during the interval 0025 to 0050 UT) and also crossed the shortlived faint arc poleward of the main auroral emission at 0051 UT and the localized brightenings within the expanded area of auroral emissions after $\sim 0100$ UT (all observed by Cluster 3). Variations in the field-aligned Poynting flux, the parallel-to-perpendicular integrated electron energy flux and the high $(\sim 3 \mathrm{keV})$ and low $(\sim 500 \mathrm{eV})$ electron differential energy fluxes were very similar to those observed by Cluster 3. The magnetospheric field and plasma structures observed by these satellites must therefore have spanned a region of the magnetosphere comparable in size to the satellite separation distance (approximately $1100 \mathrm{~km}$ throughout the interval presented in Figure 6).

[54] Previous studies [e.g., Wygant et al., 2000; Keiling et al., 2002] have compared in situ magnetospheric electric and magnetic field measurements with space-based auroral imagery to study the relationship between Alfvén wave Poynting flux and auroral features. In the case presented above, there was no one-to-one correspondence between peaks in Poynting flux observed at Cluster and peaks in auroral brightness due to omega bands. However, the average field-aligned Poynting flux measured by Cluster 3 and 4 during the first hour of the interval presented in Figure 8 (when omega bands were observed at the satellite footprints) was more than five times higher than during the following hour (when no omega bands were observed). Also, the average field-aligned Poynting flux observed by Cluster 1 during the 0000 to 0100 UT period (as it overflew the region poleward of the omega bands) was only $20-30 \%$ of that observed by Cluster 3 and 4 (as they cut through the omega bands).

[55] To identify Alfvén wave activity at the satellite location, we compared the ratio of the two perpendicular perturbation fields, $\delta E$ and $\delta B$, to the local Alfvén speed [Keiling, 2009]. Given the significant residual field that remained after the T01 model magnetic field was subtracted from the Cluster data (Figure 6), we have not used the T01 to determine the local magnetic field direction. Instead, we estimate $\mathbf{B}$ at the satellite by applying a 10 min running average to the FGM data. Electric and magnetic field vectors are then transformed into a field-aligned coordinate system $(l, m, n)$, such that the $n$ axis is directed parallel to $\mathbf{B}$; the $m$ axis is perpendicular to the $n$ axis and the $\mathrm{Z}_{G S M}$ direction; the $l$ axis completes the right-handed set and is perpendicular to both $m$ and $n$. Given the approximately Earthward directed field at the satellite's position, $l$ is directed perpendicular to $\mathbf{B}$ and approximately northward, $m$ is directed perpendicular to $\mathbf{B}$ and approximately eastward. 

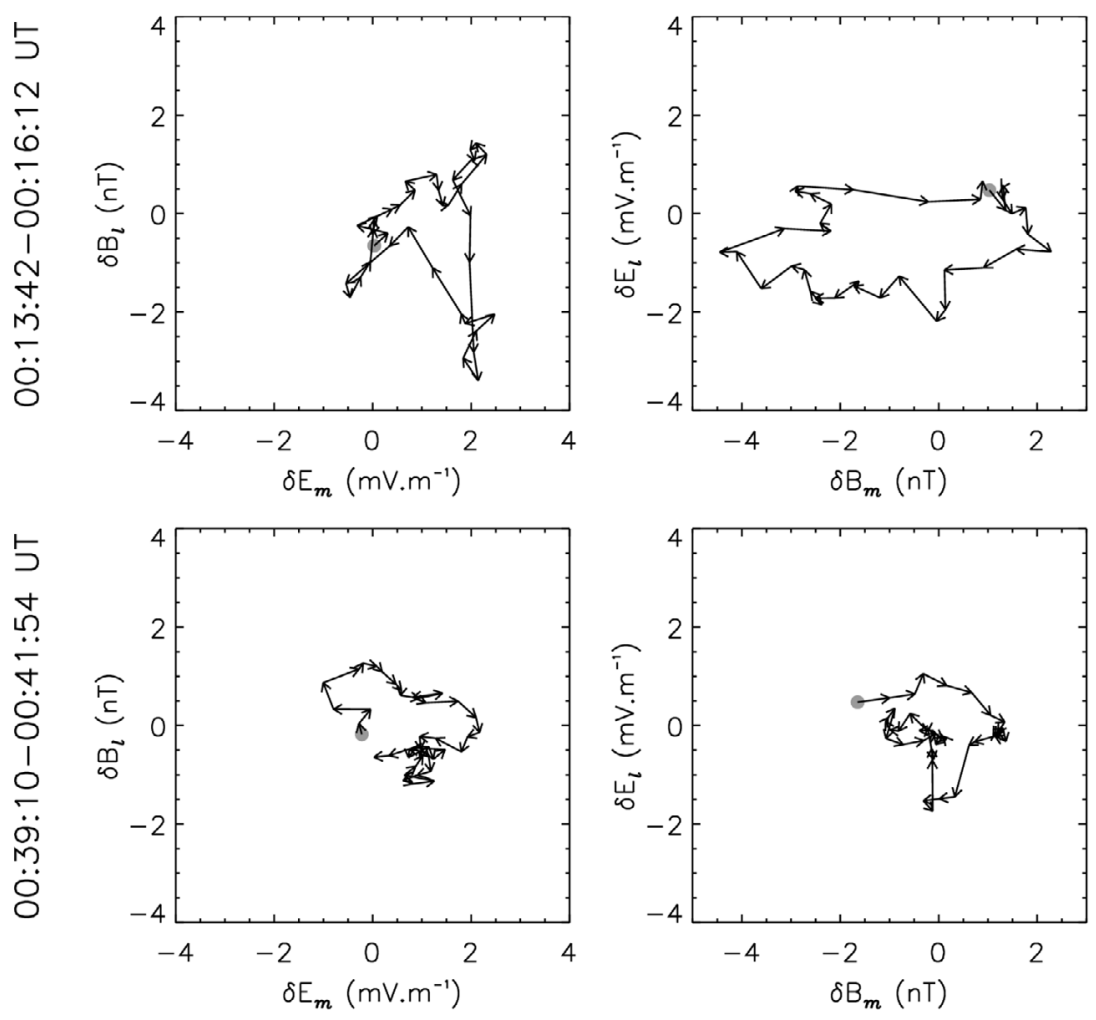

Figure 9. Hodograms showing electric and magnetic field perturbations in the plane perpendicular to the magnetic field at the Cluster 3 satellite at (top) $\sim 0015$ UT and (bottom) $\sim 0040$ UT. (left) At each time, the hodogram shows the relationship between the $\delta B_{l}$ and $\delta E_{m}$ perturbations; (right) the hodogram shows the relationship between the $\delta E_{l}$ and $\delta B_{m}$ perturbations. The exact time range of each pair is indicated on the left and the starting position is shown by a shaded gray circle in each panel. Arrowed vectors join adjacent measurements (recorded at $4 \mathrm{~s}$ resolution).

[56] Figure 9 shows example hodograms, derived from the field-perpendicular electric and magnetic field fluctuations measured by Cluster 3 . The approximately circular loci of points demonstrate that the phase relationship between the $\delta B_{l}$ and $\delta E_{m}$ components (and the relationship between $\delta E_{l}$ and $\delta B_{m}$ components) is $\sim 90^{\circ}$. This suggests that the observed field perturbations are a result of propagating shear Alfvén waves. Between 0030 and 0100 UT, the fieldperpendicular component of the electric field perturbations $\left(\delta E_{\perp}^{2}=\delta E_{l}^{2}+\delta E_{m}^{2}\right)$ varied between 0.5 and $2.0 \mathrm{mV} \mathrm{m}^{-1}$, with a mean of $1.0 \mathrm{mV} \mathrm{m}^{-1}$; the equivalent component of the magnetic field perturbations $\left(\delta B_{\perp}^{2}=\delta B_{l}^{2}+\delta B_{m}^{2}\right)$ varied between 0.5 and $5.0 \mathrm{nT}$, with a mean of $2.1 \mathrm{nT}$. The resulting $\mathrm{E} / \mathrm{B}$ fluctuation ratio varied between 100 and $2500 \mathrm{~km} \mathrm{~s}^{-1}$, with a mean ratio of $1062 \mathrm{~km} \mathrm{~s}^{-1}$. This is comparable to the local Alfvén speed of $\sim 1000 \mathrm{~km} \mathrm{~s}^{-1}$, based upon Cluster in situ field and plasma parameters. The field-aligned Poynting flux and the correlated electric and magnetic field perturbations observed at Cluster 3 are thus consistent with the propagation of shear Alfvén waves along the magnetic field. Crucially, the field-parallel Poynting vector at Cluster 3 and 4 is almost always positive, implying wave energy is being transferred from the plasma sheet to the ionosphere and is not reflected. This is consistent with the propagating shear Alfvén waves described by Watt and Rankin [2010] and may account for the source of the accelerated particle energy.
[57] Although a one-to-one causal relationship cannot be found, the overall picture that emerges from the in situ magnetospheric data suggests shear Alfvén wave activity in the plasma sheet-accelerated electrons, typically with energy $<3 \mathrm{keV}$, Earthward along the magnetic field line from a location tailward of the Cluster 3 and 4 satellites $\left(>8 R_{E}\right.$ downtail). In situ values of Poynting flux can be extrapolated to ionospheric altitudes by multiplying the in situ flux by a factor equal to the ratio of the background magnetic field strength at the location of the in situ measurements to the magnetic field strength at ionospheric altitude [Wygant et al., 2000]. Using values of $\sim 50 \mathrm{nT}$ for the in situ field (observed by Cluster 3 at 0030 UT) and an ionospheric field at $110 \mathrm{~km}$ of 50,000 nT, the amplification factor due to the converging field lines in the vicinity of the Earth is $\sim 1000$. Consequently, the field-aligned Poynting flux observed by Cluster 3 and 4 corresponded to a flux at ionospheric altitude of up to $100 \mathrm{~mW} \mathrm{~m}^{-2}$, but averaging 17 and $13 \mathrm{~mW} \mathrm{~m}^{-2}$ for Cluster 3 and 4, respectively, between 0000 and 0100 UT.

[58] In a statistical study of 40 plasma sheet crossings by the Polar satellite, Keiling et al. [2002] compared mapped (ionospheric) peak Poynting flux with electron energy flux estimated from ultraviolet auroral images. They concluded that Alfvénic Poynting flux in the midtail region $\left(4-7 R_{E}\right)$ is associated with and capable of powering localized regions of magnetically conjugate auroral emissions. Recent modeling work by Watt and Rankin [2010] indicated that in 
warm plasmas (such as the tail plasma sheet), electrons become trapped in shear Alfvén waves, are accelerated, producing field-aligned beams likely to result in auroral brightening. Although the Poynting fluxes observed in this study are at the lower range of those reported by Keiling et al. [2002], we interpret the observation of enhanced and variable Alfvénic Poynting flux, accompanied by bursts of field-aligned electron flux in the plasma sheet during an interval in which auroral omega bands were observed, as evidence that these auroral structures are related to beams of electrons accelerated in the midtail plasma sheet.

\subsection{Omega Band Structure and Formation}

[59] The omega bands observed on the night of 27-28 September 2009 were somewhat atypical in several respects. First, they were observed close to magnetic midnight, whereas the vast majority of previous studies classified omega bands as a morning sector phenomenon. Second, the omega bands presented here were observed a few minutes after a substorm expansion phase onset (based upon magnetic field measurements and global auroral indices), rather than during the substorm recovery phase as is usually reported. Specifically, in this case study, the omega bands appear to emerge from the onset region located in the premidnight sector just westward (duskward) of the Tjörnes ASI. Although relatively small $(\sim 200 \mathrm{~km}$ scale size $)$, the omega bands drifted eastward, i.e., away from the onset region and toward dawn, at $\sim 0.4 \mathrm{~km} \mathrm{~s}^{-1}$. Given that Lühr and Schlegel [1994] argued that omega bands and Ps6 pulsations are "essentially the same phenomenon seen by different instruments", the magnetic measurements presented above confirm that the optical signatures observed were indeed omega bands (albeit relatively small, slowly moving examples).

[60] Although previous studies [e.g., Lühr and Schlegel, 1994; Wild et al., 2000] have reported strong ionospheric plasma velocity shears at the boundary between the bright and dark regions of the omega band, there is little evidence of this effect in the features presented here. As indicted earlier, at the relatively short range $(\sim 250 \mathrm{~km})$ at which the SuperDARN Iceland East radar was sounding the auroral oval, it is likely that the radar pulses were being backscattered by $E$ (rather than $F$ ) region ionospheric plasma irregularities. Because of collisions between ionospheric ions and atmospheric neutrals, a two-stream instability limits the speed of the $E$ region electron density irregularities exploited by the radar as backscatter targets [Robinson, 1986]. Furthermore, due to the line-of-sight nature of the radar measurements, only a component of the true flow is measured by a single radar. As a result, the radar data presented above may have underestimated the true ionospheric plasma flow velocity.

[61] Uncertainties in the magnetic field model make detailed comparisons between ionospheric and magnetospheric measurements difficult. The superior temporal and spatial resolution of the ground-based auroral images available here (at least an order of magnitude higher than auroral image data yielded by space-based imagers, both spatially and temporally) highlights limitations in the mapping capability. Despite the lack of a one-to-one correlation between auroral features and satellite measurements, the in situ data suggest that electrons accelerated in the midtail plasma sheet powered auroral emissions during the interval in which the omega bands were observed.

[62] An interesting question left unanswered by this study is that of the fate of the omega bands after they left the Tjörnes ASI field of view. It is not clear whether these structures continued to propagate eastward and, if they did, how they evolved as they moved through the morning sector. Although we have been unable to find clear-sky auroral images from Scandinavia for this interval, IMAGE magnetometer data from the Scandinavian sector indicated Ps6 pulsation activity. This raises the possibility that stable omega bands might propagate dawnward over many hours of magnetic local time, retreating from the substorm onset region in the vicinity of the midnight sector. If true, this could account for the general association between omega bands and the substorm recovery phase. If, as in the case study presented above, omega bands are formed in the vicinity of the midnight sector shortly after expansion onset/ intensification, a steady eastward propagation would imply a delay before their observation in the morning/dawn sector. Eastward motion over $4 \mathrm{~h}$ of MLT at $0.4-2.0 \mathrm{~km} \mathrm{~s}^{-1}$ would take between 20 and $100 \mathrm{~min}$ (at $68^{\circ}$ magnetic latitude), implying that faster moving omega bands launched eastward from substorm onset in the midnight sector would arrive in the morning sector during the substorm recovery phase. Given the growing international archive of space- and ground-based auroral imagery that provides regional and global auroral imaging capabilities and multisatellite magnetosphere satellite missions, this question should be resolvable in the future.

[63] Omega bands have traditionally been linked with the substorm recovery phase [e.g., Opgenoorth et al., 1994] and associated with Ps6 magnetic pulsations in ground magnetometer data [André and Baumjohann, 1982; Opgenoorth et al., 1983; Steen et al., 1988]. However, a variety of studies have linked these ionospheric phenomena to sources in the magnetosphere. For example, Steen et al. [1988] suggested that variations in the high-energy particle intensity at geosynchronous orbit are responsible for the generation of auroral omega bands, a proposal later supported by the findings of Tagirov [1993], who used the Tsyganenko T89 magnetospheric magnetic field model to demonstrate that auroral torches map to the equatorial plane 5-6 $R_{E}$ from the Earth. Subsequent studies linked omega bands to the magnetotail plasma sheet, with Jorgensen et al. [1999] concluding that they are the electrodynamic signature of the corrugated inner edge of a current sheet in the vicinity of geostationary orbit. Pulkkinen et al. [1991] exploited the Tsyganenko model to show that the omega bands and Ps6 pulsation map to the current sheet approximately 6-13 $R_{E}$ downtail from the Earth.

[64] Despite growing evidence that the source region of omega bands/Ps6 pulsations lies in (or at the boundary of) the current sheet, the source mechanism remains unclear. Proposed mechanisms include the development of the KelvinHelmholtz instability at the boundary between the boundary layer plasma sheet and the central plasma sheet due to flow shear [Rostoker and Samson, 1984], an interchange instability developing on the outer boundary of a hot plasma torus [Yamamoto et al., 1997], and spatially periodic electron precipitation caused by field-aligned electric fields generated by waves excited on the corrugated inner edge of the current 
sheet [Jorgensen et al., 1999]. Although the observations presented in our study favor a process that generates earthward Alfvénic Poynting flux in the plasma sheet (tailward of geostationary orbit), it is unclear how an electronaccelerating mechanism in the tail might result in stable, azimuthally propagating auroral features that migrate to the morning/dawn sector, unless the source in the tail also spanned a range of local times. Further simultaneous, multipoint, in situ measurements are required to confidently validate or discount the previously proposed mechanisms (e.g., at azimuthally displaced locations at the inner edge of the plasma sheet).

\section{Conclusions}

[65] This study presents space- and ground-based observations of a series of omega bands in the midnight sector auroral ionosphere just after midnight on 28 September 2009. Specifically, this study exploited a ground-based auroral all-sky imager, magnetometer and coherent scatter high-frequency radar to diagnose the electrodynamics of the auroral structures. Simultaneous upstream solar wind and IMF measurements were provided by the THEMIS $\mathrm{C}$ probe, and in situ field and plasma measurement from the tail plasma sheet were provided by the four Cluster satellites in magnetic conjunction with the ground-based experiments. The results of the study can be summarized as follows.

[66] 1. A train of at least five clear auroral omega bands was observed, the first occurring within 5 min of a substorm expansion phase intensification during an interval of steady southward and duskward oriented IMF and unremarkable solar wind conditions $\left(\sim 320 \mathrm{~km} \mathrm{~s}^{-1}\right.$ Earthward speed and $\sim 2.5 \mathrm{nPa}$ dynamic pressure).

[67] 2. The substorm onset and intensification occurred in the immediate premidnight/midnight sector (2300-2400 MLT) with the omega bands emerging in the immediate postmidnight sector ( 0000-0030 MLT). The omega bands, which were smaller (scale size $\sim 200 \mathrm{~km}$ ) than in many previous studies [e.g., Akasofu, 1964; Lühr, 1994; Wild et al., 2000], propagated eastward (dawnward) away from the onset region at $\sim 400 \mathrm{~m} \mathrm{~s}^{-1}$ (i.e., at the lower end of eastward propagation speeds reported by Opgenoorth et al. [1983] and Steen et al. [1988]).

[68] 3. The optical auroral features were accompanied by Ps6 magnetic pulsations, consistent with the passage of vortical ionospheric Hall currents associated with upward/ downward field-aligned currents over the magnetometer.

[69] 4. There was no compelling evidence that the omega bands were associated with an ionospheric flow shear at the poleward boundary of the main auroral oval, but this cannot be confirmed conclusively due to limited radar backscatter in the region poleward of the main oval. The average ionospheric flow inside the main auroral oval was between 100 and $250 \mathrm{~m} \mathrm{~s}^{-1}$ away from the radar throughout, consistent with dawnward flow in the dawn cell of the global ionospheric convection pattern.

[70] 5. The Cluster satellites, located in the tail plasma sheet observed transient bursts of electron differential energy flux, including dispersed energy signatures, throughout the interval when omega bands were observed in the vicinity of the satellite footprints. During the conjunction, generally enhanced Alfvénic Poynting flux was observed. Although variable in magnitude, the field-parallel Poynting flux was almost continuously directed toward the Northern Hemisphere. Electron plasma measurements indicated that electrons with energies $<3 \mathrm{keV}$ were accelerated in the field-aligned direction.

[71] 6. A one-to-one correlation between in situ plasma observations and the auroral structures was not found, perhaps due to limitations in the magnetospheric field model.

[72] Our observations agree with previous studies suggesting that omega bands have a source mechanism in the plasma sheet, tailward of geostationary orbit. However, the somewhat unusual magnetic local time of the structures presented here and their observation during the early substorm expansion phase hints that these features may not be restricted to the morning sector and the substorm recovery phase (as is often stated in the literature). This is consistent with the findings of Connors et al. [2003], who reported that Ps6 pulsations (considered to be the magnetic manifestation of auroral omega bands) can occur at or very near the time of onset of a substorm expansive phase, a pseudobreakup, or a poleward boundary intensification.

[73] We suggest that a survey of contemporary auroral imagery data sets (such as the archive of the North American THEMIS GBO network) may provide cradle-to-grave observations of omega band formation at substorm onset near the midnight sector and propagation over many hours of MLT into the late morning sector during the substorm recovery phase. Such observations might suggest that the common generation mechanism for Ps6 pulsations and omega bands can be found during the substorm expansion phase, rather than the recovery phase.

[74] Acknowledgments. For the provision of experimental equipment and technical support, J.A.W. and E.E.W. are indebted to the auroral imaging team at the Institute for Space Research at the University of Calgary. J.A.W. and E.E.W. were supported during this study by UK Science and Technology Facilities Council grant PP/E001947/1 while R.C.F., A.G., and M.L. were supported by STFC grant ST/H002480/1. SuperDARN operations at the University of Leicester are supported by STFC grant PP/ E007929/1. Cluster operations in the UK were supported by the STFC. We acknowledge NASA contract NAS5-02099 and financial support through the German Ministry for Economy and Technology and the German Center for Aviation and Space (DLR) under contract 50 OC 0302 for the THEMIS data used in this study. J.A.W. is especially grateful to $\mathrm{J}$. Hohl of UCLA for assistance in the preparation of this paper.

[75] Robert Lysak thanks I. Rae and the reviewers for their assistance in evaluating this paper.

\section{References}

Akasofu, S. I. (1964), The development of the auroral substorm, Planet. Space Sci., 12(4), 273-282.

Akasofu, S. I., and D. S. Kimball (1964), The dynamics of the aurora: I. Instabilities of the aurora, J. Atmos. Terr. Phys., 26, 205-211.

Amm, O., A. Aksnes, J. Stadsnes, N. Østgaard, R. R. Vondrak, G. A. Germany, G. Lu, and A. Viljanen (2005), Mesoscale ionospheric electrodynamics of omega bands determined from ground-based electromagnetic and satellite optical observations, Ann. Geophys., 23, 325-342.

André, D., and W. Baumjohann (1982), Joint two-dimensional observations of ground magnetic and ionospheric electric fields associated with auroral currents. 5. Current system associated with eastward drifting omega bands, J. Geophys., 50, 194-201.

Angelopoulos, V. (2008), The THEMIS mission, Space Sci. Rev., 141, 5-24, doi:10.1007/s11214-008-9336-1.

Auster, H. U., et al. (2008), The THEMIS fluxgate magnetometer, Space Sci. Rev., 141(1-4), 235-264, doi:10.1007/s11214-008-9365-9.

Balogh, A., et al. (1997), The Cluster magnetic fields investigation, Space Sci. Rev., 79, 65-91.

Balogh, A., et al. (2001), The Cluster magnetic field investigation: Overview of in-flight performance and initial results, Ann. Geophys., 19, 1207-1217. 
Chisham, G., et al. (2007), A decade of the Super Dual Auroral Radar Network (SuperDARN): Scientific achievements, new techniques and future directions, Surv. Geophys., 28, 33-109, doi:10.1007/s10712-0079017-8.

Connors, M., G. Rostoker, G. Sofko, R. L. McPherron, and M. G. Henderson (2003), Ps 6 disturbances: Relation to substorms and the auroral oval, Ann. Geophys., 21, 493-508.

Escoubet, C. P., R. Schmidt, and M. L. Goldstein (1997), Cluster-Science and mission overview, Space Sci. Rev., 79, 391-391.

Escoubet, C. P., M. Fehringer, and M. L. Goldstein (2001), The Cluster mission, Ann. Geophys., 19, 1197-1200.

Frey, H. U., S. B. Mende, and V. Angelopoulos (2004), Substorm onset observations by IMAGE-FUV, J. Geophys. Res., 109, A10304, doi:10.1029 2004JA010607.

Grocott, A., S. W. H. Cowley, J. B. Sigwarth, J. F. Watermann, and T. K. Yeoman (2002), Excitation of twin-vortex flow in the nightside highlatitude ionosphere during an isolated substorm, Ann. Geophys., 20(10), 1577-1601, doi:10.5194/angeo-20-1577-2002.

Grocott, A., T. K. Yeoman, R. Nakamura, S. W. H. Cowley, H. U. Frey, H. Rème, and B. Klecker (2004), Multi-instrument observations of the ionospheric counterpart of a bursty bulk flow in the near-earth plasma sheet, Ann. Geophys., 22(4), 1061-1075, doi:10.5194/angeo-22-1061-2004.

Gustafsson, G., et al. (1997), The electric field and wave experiment for the Cluster mission, Space Sci. Rev., 79(1-2), 137-156.

Gustafsson, G., et al. (2001), First results of electric field and density observations by Cluster EFW based on initial months of operation, Ann. Geophys., 19(10-12), 1219-1240.

Janhunen, P., and A. Huuskonen (1993), A numerical ionospheremagnetosphere coupling model with variable conductivities, J. Geophys Res., 98, 9519-9530, doi:10.1029/92JA02973.

Johnstone, A. D., et al. (1997), PEACE: A Plasma Electron and Curren instrument, Space Sci. Rev., 79, 351-398.

Jorgensen, A. M., H. E. Spence, T. J. Hughes, and D. McDiarmid (1999), A study of omega bands and Ps6 pulsations on the ground, at low altitude and at geostationary orbit, J. Geophys. Res., 104, 14,705-14,715.

Kavanagh, A. J., J. A. Wild, and F. Honary (2009), Observations of omega bands using an imaging riometer, Ann. Geophys., 27(11), 4183-4195.

Kawasaki, K., and G. Rostoker (1979), Perturbation magnetic fields and current systems associated with eastward drifting auroral structures, J. Geophys. Res., 84, 1464-1480, doi:10.1029/JA084iA04p01464.

Keiling, A. (2009), Alfvén waves and their roles in the dynamics of the Earth's magnetotail: A review, Space Sci. Rev., 142(1-4), 73-156, doi:10.1007/s11214-008-9463-8.

Keiling, A., J. R. Wygant, C. Cattell, W. Peria, G. Parks, M. Temerin, F. S. Mozer, C. T. Russell, and C. A. Kletzing (2002), Correlation of Alfvén wave Poynting flux in the plasma sheet at 4-7 $R_{E}$ with ionospheric electron energy flux, J. Geophys. Res., 107(A7), 1132, doi:10.1029 2001JA900140.

Lester, M., et al. (2004), Stereo CUTLASS-A new capability for the SuperDARN HF radars, Ann. Geophys., 22, 459-473.

Lühr, H. (1994), The image magnetometer network, STEP Int. Newsl., $4(10), 4$

Lühr, H., and K. Schlegel (1994), Combined measurements of EISCAT and the EISCAT magnetometer cross to study omega bands, J. Geophys. Res., 99(A5), 8951-8959.

Lyons, L. R., and R. L. Walterscheid (1985), Generation of auroral omega bands by shear instability of the neutral winds, J. Geophys. Res., 90 12,321, doi:10.1029/JA090iA12p12321.

McFadden, J. P., C. W. Carlson, D. Larson, V. Angelopoulos, M. Ludlam, R. Abiad, B. Elliott, P. Turin, and M. Marckwordt (2008a), The THEMIS ESA plasma instrument and in-flight calibration, Space Sci. Rev. 141(1-4), 277-302, doi:10.1007/s11214-008-9440-2.

McFadden, J. P., C. W. Carlson, D. Larson, J. Bonnell, F. Mozer V. Angelopoulos, K.-H. Glassmeier, and U. Auster (2008b), THEMIS ESA first science results and performance issues, Space Sci. Rev. 141(1-4), 477-508, doi:10.1007/s11214-008-9433-1.

Opgenoorth, H. J., J. Oksman, K. U. Kaila, E. Nielsen, and W. Baumjohann (1983), Characteristic of eastward drifting omega bands in the morning sector, J. Geophys. Res., 88, 9171-9185.

Opgenoorth, H. J., M. A. L. Persson, T. I. Pulkkinen, and R. J. Pellinen (1994), Recovery phase of magnetospheric substorms and its association with morning-sector aurora, J. Geophys. Res., 99, 4115-4129, doi:10.1029/93JA01502

Owen, C. J., et al. (2001), Cluster peace observations of electrons during magnetospheric flux transfer events, Ann. Geophys., 19, 1509-1522.

Partamies, N., M. Syrjäsuo, and E. Donovan (2007), Using colour in auroral imaging, Can. J. Phys., 85(2), 101-109.

Pulkkinen, T. I., R. J. Pellinen, H. E. J. Koskinen, H. J. Opgenoorth, J. S Murphree, V. Petrov, A. Zaitsev, and E. Friis-Christensen (1991), Auro- ral signatures of substorm recovery phase: A case study, in Magnetospheric Substorms, Geophys. Monogr. Ser., vol. 64, edited by J. R. Kan et al., pp. 333-342, AGU, Washington, D. C.

Robinson, T. R. (1986), Towards a self-consistent non-linear theory of radar auroral backscatter, J. Atmos. Terr. Phys., 48, 417-422.

Rostoker, G., and J. S. Samson (1984), Can substorm expansive phase effects and low frequency Pc magnetic pulsations be attributed to the same source mechanism?, Geophys. Res. Lett., 1, 271-274.

Safargaleev, V., T. Sergienko, H. Nilsson, A. Kozlovsky, S. Massetti, S. Osipenko, and A. Kotikov (2005), Combined optical, EISCAT and magnetic observations of the omega bands/Ps6 pulsations and an auroral torch in the late morning hours: A case study, Ann. Geophys., 23, 1821-1838.

Sato, N., and T. Saemundsson (1984), Conjugacy of electron auroras observed by all-sky cameras and scanning photometers, Mem. Natl. Inst Polar Res., Spec. Issue 48, 58-71.

Shue, J.-H., J. K. Chao, H. C. Fu, C. T. Russell, P. Song, K. K. Khurana, and H. J. Singer (1997), A new functional form to study the solar wind control of the magnetopause size and shape, J. Geophys. Res., 102, 9497-9511

Steen, A., P. N. Collis, D. Evans, G. Kremser, S. Capelle, D. Rees, and B. T. Tsurutani (1988), Observation of a gradual transition be- tween Ps6 activity within auroral torches and surgelike pulsations during strong geomagnetic disturbances, J. Geophys. Res., 93, 8713-8733.

Syrjäsuo, M., and E. Donovan (2004), Diurnal auroral occurrence statistics obtained via machine vision, Ann. Geophys., 22, 1103-1113.

Tagirov, V. (1993), Auroral torches: Results of optical observations, J. Atmos. Terr. Phys., 55, 1775-1787.

Tsyganenko, N. A. (1995), Modelling the Earth's magnetospheric magnetic field confined within a realistic magnetopause, J. Geophys. Res., 100, 5599-5612, doi:10.1029/94JA03193.

Tsyganenko, N. A. (2002a), A model of the near magnetosphere with dawn-dusk asymmetry: 1. Mathematical structure, J. Geophys. Res., 107(A8), 1179, doi:10.1029/2001JA000219.

Tsyganenko, N. A. (2002b), A model of the near magnetosphere with a dawn-dusk asymmetry: 2. Parameterization and fitting to observations, J. Geophys. Res., 107(A8), 1176, doi:10.1029/2001JA000220.

Vanhamäki, H., K. Kauristie, O. Amm, A. Senior, D. Lummerzheim, and S. Milan (2009), Electrodynamics of an omega-band as deduced from optical and magnetometer data, Ann. Geophys., 27, 3367-3385.

Watt, C. E. J., and R. Rankin (2010), Do magnetospheric shear Alfvén waves generate sufficient electron energy flux to power the aurora?, J. Geophys. Res., 115, A07224, doi:10.1029/2009JA015185.

Wild, J. A., T. K. Yeoman, P. Eglitis, and H. J. Opgenoorth (2000), Multiinstrument observations of the electric and magnetic field structure of omega bands, Ann. Geophys., 18, 99-110.

Wygant, J., et al. (2000), Polar spacecraft based comparisons of intense electric fields and Poynting flux near and within the plasma sheet-tail lobe boundary to UVI images: An energy source for the aurora, J. Geophys. Res., 105(A8), 18,675-18,692.

Yamamoto, T., S. Inoue, and C. Meng (1997), Formation of auroral omega bands in the paired region 1 and region 2 field-aligned current system, J. Geophys. Res., 102, 2531-2544, doi:10.1029/96JA02456.

M. Andre and Y. Khotyaintsev, Swedish Institute of Space Physics, Uppsala, SE-751 21, Sweden.

V. Angelopoulos, Institute of Geophysics and Planetary Physics/ESS, University of California, Los Angeles, CA 90095, USA.

G. Björnsson, Science Institute, University of Iceland, IS-107 Reykjavik, Iceland

C. Carlson and J. P. McFadden, Space Sciences Laboratory, University of California, Berkeley, CA 94720, USA.

E. Donovan, Department of Physics and Astronomy, University of Calgary, Calgary, AB T2N 1N4, Canada.

A. N. Fazakerley, Mullard Space Science Laboratory, University College London, Holmbury St. Mary RH5 6NT, UK.

R. C. Fear, A. Grocott, and M. Lester, Department of Physics and Astronomy, University of Leicester, Leicester LE1 7RH, UK.

K. H. Glassmeier, Institut für Geophysik und Extraterrestrische Physik, Technische Universität Braunschweig, D-38106 Braunschweig, Germany.

$\mathrm{K}$. Hosokawa, Department of Information and Communication Engineering, University of Electro-Communications, 1-5-1 Chofugaoka Chofu-shi, Tokyo 182-8585, Japan

A. Kadokura, Polar Data Center, National Institute of Polar Research, 10-3 Midoricho, Tachikawa, Tokyo 190-8518, Japan.

E. Lucek, Department of Physics, Imperial College London, London SW7 2AZ, UK.

J. A. Wild and E. E. Woodfield, Physics Department, Lancaster University, Lancaster, LA1 4YB, UK. (j.wild@lancaster.ac.uk) 